ARTICLE

https://doi.org/10.1038/s41467-019-08438-0

\title{
The antimicrobial potential of Streptomyces from insect microbiomes
}

Marc G. Chevrette (1) 1,2, Caitlin M. Carlson², Humberto E. Ortega ${ }^{3}$, Chris Thomas ${ }^{4}$, Gene E. Ananiev ${ }^{5}$, Kenneth J. Barns ${ }^{4}$, Adam J. Book ${ }^{2}$, Julian Cagnazzo ${ }^{2}$, Camila Carlos ${ }^{2}$, Will Flanigan², Kirk J. Grubbs ${ }^{2}$, Heidi A. Horn², F. Michael Hoffmann ${ }^{5}$, Jonathan L. Klassen ${ }^{6}$, Jennifer J. Knack (1) 7, Gina R. Lewin ${ }^{8}$, Bradon R. McDonald (10 2 ${ }^{2}$, Laura Muller ${ }^{2}$, Weilan G.P. Melo (1) ${ }^{3}$, Adrián A. Pinto-Tomás ${ }^{9}$, Amber Schmitz ${ }^{2}$, Evelyn Wendt-Pienkowski ${ }^{2}$, Scott Wildman ${ }^{4}$, Miao Zhao ${ }^{10}$, Fan Zhang ${ }^{4}$, Tim S. Bugni ${ }^{4}$, David R. Andes ${ }^{10}$, Monica T. Pupo (iD ${ }^{3} \&$ Cameron R. Currie ${ }^{2}$

Antimicrobial resistance is a global health crisis and few novel antimicrobials have been discovered in recent decades. Natural products, particularly from Streptomyces, are the source of most antimicrobials, yet discovery campaigns focusing on Streptomyces from the soil largely rediscover known compounds. Investigation of understudied and symbiotic sources has seen some success, yet no studies have systematically explored microbiomes for antimicrobials. Here we assess the distinct evolutionary lineages of Streptomyces from insect microbiomes as a source of new antimicrobials through large-scale isolations, bioactivity assays, genomics, metabolomics, and in vivo infection models. Insect-associated Streptomyces inhibit antimicrobial-resistant pathogens more than soil Streptomyces. Genomics and metabolomics reveal their diverse biosynthetic capabilities. Further, we describe cyphomycin, a new molecule active against multidrug resistant fungal pathogens. The evolutionary trajectories of Streptomyces from the insect microbiome influence their biosynthetic potential and ability to inhibit resistant pathogens, supporting the promise of this source in augmenting future antimicrobial discovery.

\footnotetext{
${ }^{1}$ Laboratory of Genetics, University of Wisconsin-Madison, Madison 53706 WI, USA. ${ }^{2}$ Department of Bacteriology, University of Wisconsin-Madison, Madison 53706 WI, USA. ${ }^{3}$ School of Pharmaceutical Sciences of Ribeirão Preto, University of São Paulo, Ribeirão Preto $14040-903$ SP, Brazil.

${ }^{4}$ Pharmaceutical Sciences Division, School of Pharmacy, University of Wisconsin-Madison, Madison 53705 WI, USA. ${ }^{5}$ McArdle Laboratory for Cancer Research, Wisconsin Institute for Medical Research, University of Wisconsin-Madison, Madison 53705 WI, USA. ${ }^{6}$ Department of Molecular and Cell Biology, University of Connecticut, Storrs 06269 CT, USA. ${ }^{7}$ Department of Biology, Large Lakes Observatory, University of Minnesota-Duluth, Duluth 55812 MN, USA. ${ }^{8}$ School of Biological Sciences, Georgia Institute of Technology, Atlanta 30332 GA, USA. ${ }^{9}$ Center for Research in Microscopic Structures and Department of Biochemistry, School of Medicine, University of Costa Rica, San José 10102, Costa Rica. ${ }^{10}$ Department of Medicine, University of Wisconsin School of Medicine and Public Health, Madison 53705 WI, USA. Correspondence and requests for materials should be addressed to C.R.C. (email: currie@bact.wisc.edu)
} 
T he rapid emergence of antimicrobial resistance in bacterial and fungal pathogens is a public health crisis ${ }^{1,2}$. Novel therapeutics are needed to counter resistance, yet no new antimicrobial classes have been clinically approved in over three decades $^{3}$. Natural products are the main source of antimicrobials, the majority of which are produced by Actinobacteria cultured from the soil ${ }^{3,4}$. However, contemporary studies of this once prolific source of novel chemistry face dramatically diminishing returns, largely due to the rediscovery of known compounds 5 . Efforts to address this issue, including genome mining ${ }^{6,7}$, synthetic biology ${ }^{8}$, and exploring alternative microbial sources, such as marine microbial environments ${ }^{9-12}$ and underrepresented $\operatorname{taxa}^{13,14}$, have yielded limited success. To combat the continual emergence of multidrug-resistant pathogens, there is a critical and constant need to discover new antimicrobial natural products.

Natural products are the language of microbial interactions, evolved to mediate communication and antagonism among and between species ${ }^{15,16}$. Within microbiomes, the ecology and diversity of natural product chemistry reflect the underlying interactions between the microbial community, host, and environment. Exploration of the specialized natural product chemistry embedded within host microbiomes is an emerging new paradigm in antimicrobial drug discovery. Antimicrobials have recently been discovered from the microbiomes of diverse eukaryotic hosts, ranging from sea squirts ${ }^{17}$ to humans ${ }^{18}$. A particularly compelling source of novel antimicrobials lies in defensive symbioses, where bacterial symbionts produce antimicrobials to protect against opportunistic and specialized pathogens ${ }^{19-23}$. In insects, these symbioses are best exemplified in fungus-growing ant ${ }^{19-21}$, solitary digger wasp ${ }^{22}$, and southern pine beetle ${ }^{23}$ (Fig. 1a, right) systems, where Actinobacteria (typically Streptomyces) provide chemical defenses, paralleling our own reliance on the antimicrobials produced by these taxa to combat infectious disease. For example, the Streptomyces symbiotically associated with the southern pine beetle (Dendroctonus frontalis) produce the secondary metabolites frontalamide A, frontalamide $\mathrm{B}$, and mycangimycin ${ }^{23,24}$. Mycangimycin inhibits the beetles' antagonistic fungus Ophiostoma minus and has potent inhibitory activity against malaria while the frontalamides have general antifungal activity ${ }^{23,24}$. Solitary wasps also associate with Streptomyces that provide antibacterial and antifungal chemical protection to their larvae through production of streptochlorin, a variety of piericidin analogs, and other molecules ${ }^{25}$. The antifungal compound sceliphrolactam was discovered from Streptomyces associated with a mud dauber wasp ${ }^{25}$. The natalamycin derivatives produced by Streptomyces from the fungus-growing termite system provide similar antifungal defense ${ }^{26}$. Further, over 10 new natural products with antimicrobial activity have been identified from the chemical characterization of approximately

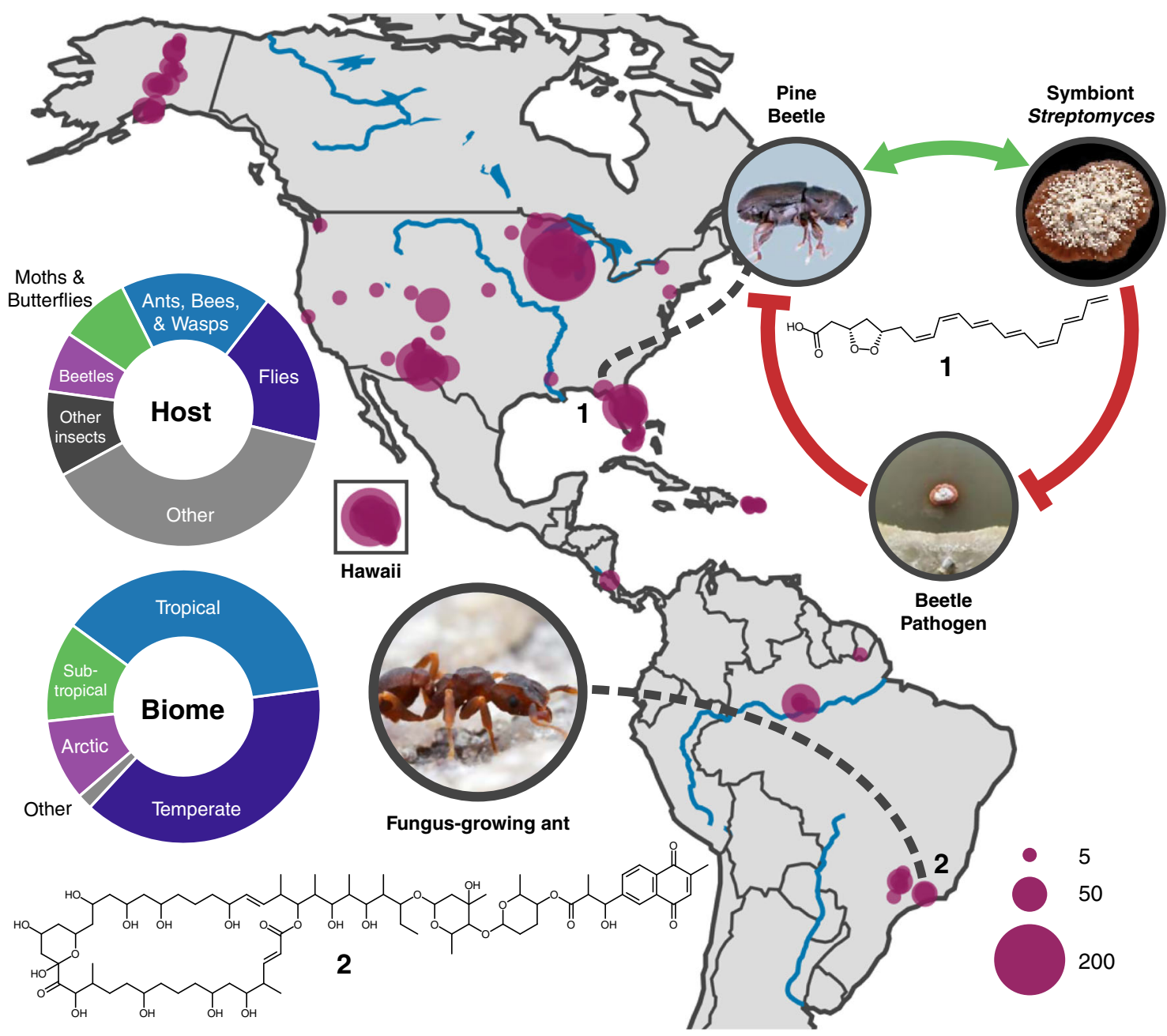

Fig. 1 Sampling strategy for Streptomyces from insect microbiomes. Streptomyces were isolated from a wide range of insects and geographies (1445 insects; 10,178 strains; dot size, insects sampled). Streptomyces production of the antifungal mycangimycin (1) in the Southern Pine Beetle system is shown at right. Cyphomycin (2) is a new antifungal described herein. Photo credits: southern pine beetle - Erich G. Vallery; fungus-growing ant - Alexander Wild 
100 insect-Streptomyces strains $23,24,27,28$. Globally there are over five million insect species that occupy virtually every terrestrial niche ${ }^{29}$. Although insects are among the most diverse organisms on the planet ${ }^{29}$, studies of Actinobacteria from these systems have been limited to only a few insect orders, specifically Hymenoptera and Coleoptera. Further, insects themselves exhibit complex chemistry that mediates and maintains the diversity of their ecological interactions ${ }^{30}$.

Here, we systematically examine our hypothesis that insect microbiomes are a valuable source of new antimicrobials. The extreme diversity of insects presents untapped potential for drug discovery from their equally diverse microbial communities. However, the breadth of natural product biosynthesis and antimicrobial potential within insect microbiomes remains relatively unknown. We hypothesize that Streptomyces from insect microbiomes represent a promising source of antimicrobials with distinct evolutionary histories from soil Streptomyces, upon which most antimicrobial discovery efforts have focused. We focus on Streptomyces because this genus: (i) is the source of most clinically used antibacterials and antifungals, (ii) has established genetic tools to facilitate development ${ }^{8}$, and (iii) has been implicated in readily forming associations with diverse insect hosts ${ }^{31}$.

\section{Results}

Streptomyces are commonly found in insect microbiomes. Counter to the prevailing assumption of Streptomyces being largely soil-associated bacteria, in our shotgun metagenome analyses, Streptomyces comparably occur in host-associated and soilassociated contexts. Specifically, we calculate the number of Streptomyces reads per megabase (rpM) to be $129.32 \mathrm{rpM}$ and $172.72 \mathrm{rpM}$ for host-associated and soil studies, respectively (data from ref. ${ }^{4}$ ). Metagenomes from freshwater (47.49 rpM) and marine $(24.65 \mathrm{rpM})$ sources are much lower in Streptomyces abundance and support the hypothesis that most Streptomyces are either soil- or host-associated.

Focusing on insect hosts, we first determined that associations between Streptomyces and insects are widespread through sampling 2561 insects spanning 15 taxonomic orders (Fig. 1, host donut chart, and Supplementary Data 1) and a wide range of geographies and biomes (Fig. 1, map and biome donut chart). Actinobacteria were isolated from 1445 of 2580 insect microbiomes (56\%) spanning 13 orders, resulting in 10,178 individual isolates, including 2934 from Hymenoptera, 2920 from Diptera, 1326 from Lepidoptera, and 1139 from Coleoptera (Supplementary Data 2). Additionally, 6935 isolates were obtained from other sources (soil: $n=833$; plants: $n=980$ ). Phylogenetic placement of 536 insect-associated and 571 free-living strains indicates that specific lineages of Streptomyces are enriched for associations with insects (Fig. 2).

Insect-Streptomyces exhibit high inhibitory activity. Through 51,050 individual antimicrobial bioactivity assays, pairing 2003 Streptomyces strains against a panel of 27 clinically and/or ecologically relevant microbes (Supplementary Data 3), we show that insect-associated strains $(n=1162)$ exhibited significantly greater inhibitory activity towards fungi, Gram-negative bacteria, and Gram-positive bacteria, compared to both soil $(n=186)$ and plant-associated $(n=178)$ Streptomyces isolates (Fig. 3a-c, Supplementary Figure 1A, and Supplementary Data 4). Specifically, insect Streptomyces strains had significantly greater antifungal activity, as indicated by inhibition fractions, the fraction of fungi for which a strain exhibited antimicrobial inhibition, where average inhibition fractions for insect-Streptomyces were $0.52 \pm$ 0.01 fraction inhibition compared to $0.42 \pm 0.02(p=9.46 \mathrm{e}-3$; $t$ test, BY correction) and $0.36 \pm 0.03(p=7.84 \mathrm{e}-7$; $t$-test, BY
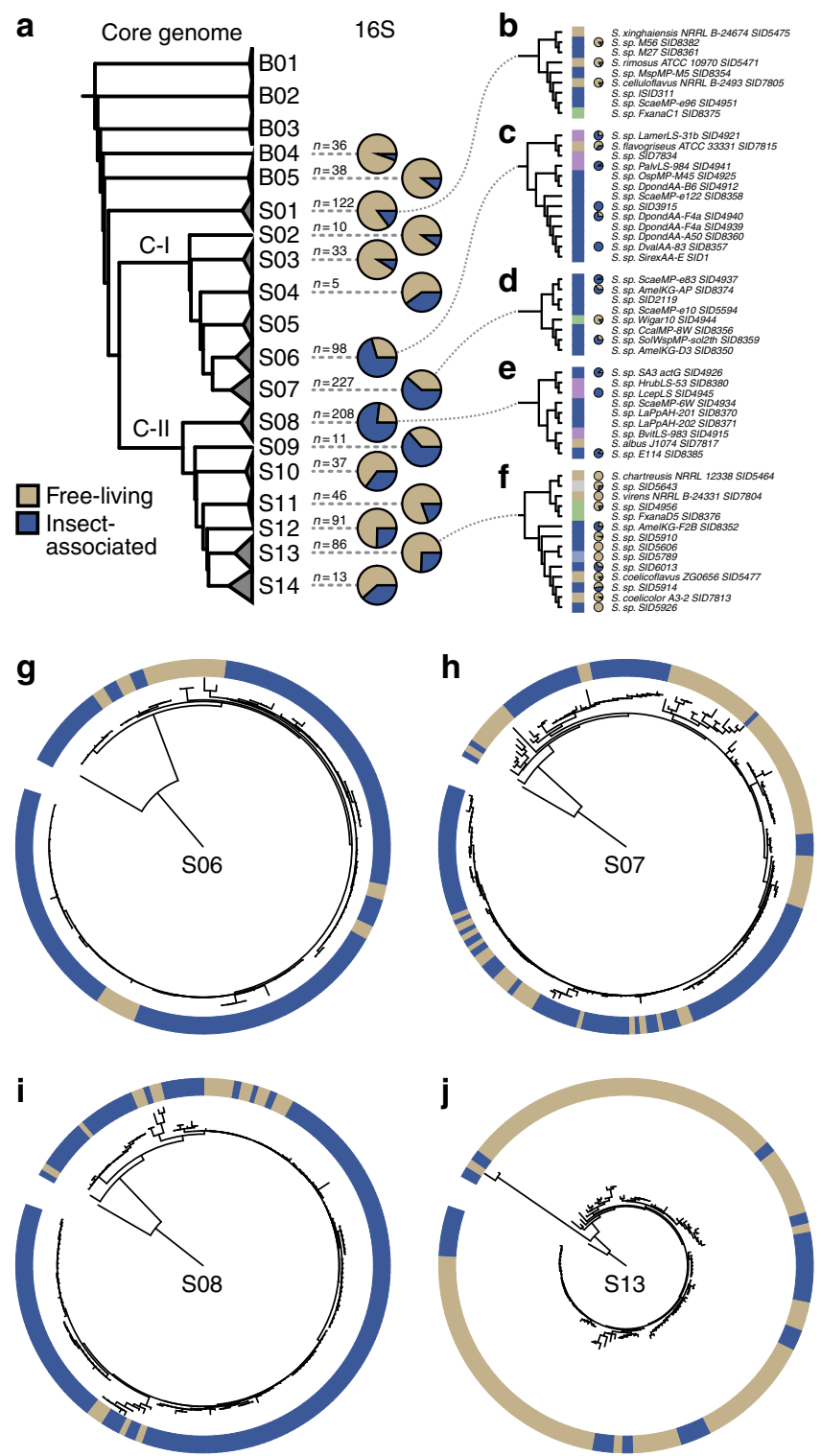

Fig. 2 Distinct lineages of Streptomyces associate with insect hosts. a A genomic phylogeny constructed from 93 single-copy core bacterial genes is shown to the left with the major clades, Clade I (C-I) and Clade II (C-II), labeled ( $B=$ Basal, $S=$ Streptomyces). $16 S$ sequences were mapped to the genomic phylogeny and the distribution of free-living (tan) and insectassociated (blue) strains is shown as both pie and bar charts to the right. Number of total strains is shown to left of pies. b-f A more detailed mapping of $16 \mathrm{~S}$ sequences onto the genomic tree is shown for clades S01 (b), S06 (c), S07 (d), S08 (e), and S13 (f). g-j 16S phylogenies from sequences mapped to clade S06 (g), S07 (h), S08 (i), and S13 (j)

correction) for soil and plant-associated strains, respectively (Fig. 3a). Against Gram-negative bacteria, insect-associated strains had an inhibition fraction of $0.26 \pm 0.01$ compared to $0.17 \pm 0.02(p=6.45 \mathrm{e}-4 ; t$-test, BY correction) and $0.12 \pm 0.02$ $(p=2.07 \mathrm{e}-7$; $t$-test, BY correction) for soil and plant-associated Streptomyces, respectively (Fig. 3b). Against Gram-positive bacteria, insect-associated strains had an inhibition fraction of $0.61 \pm$ 0.01 compared to $0.45 \pm 0.02$ ( $p=7.84 \mathrm{e}-7$; $t$-test, BY correction) and $0.34 \pm 0.03$ ( $p=7.06 \mathrm{e}-16$; $t$-test, BY correction) for soil and plant-associated strains, respectively (Supplementary Figure 1A). Some insect host orders associate with Streptomyces with especially high activity against Gram-negative bacteria and fungi 

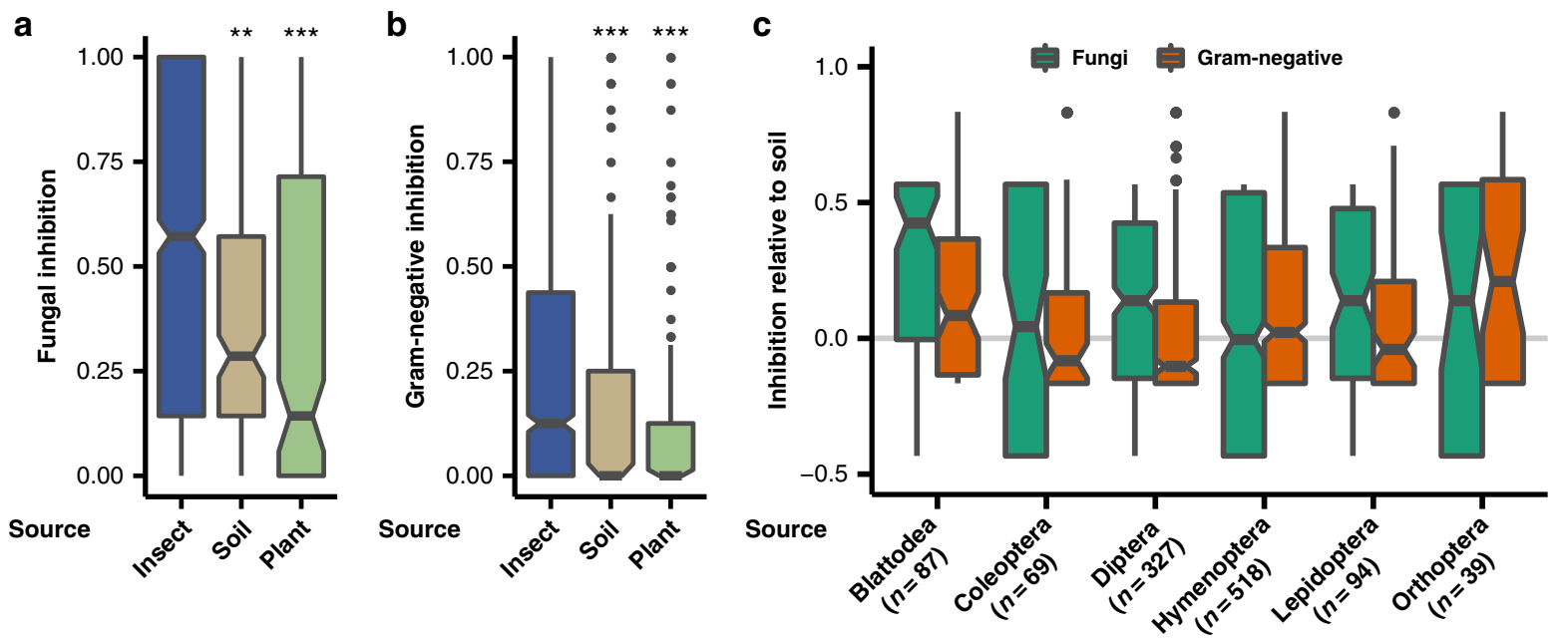

d

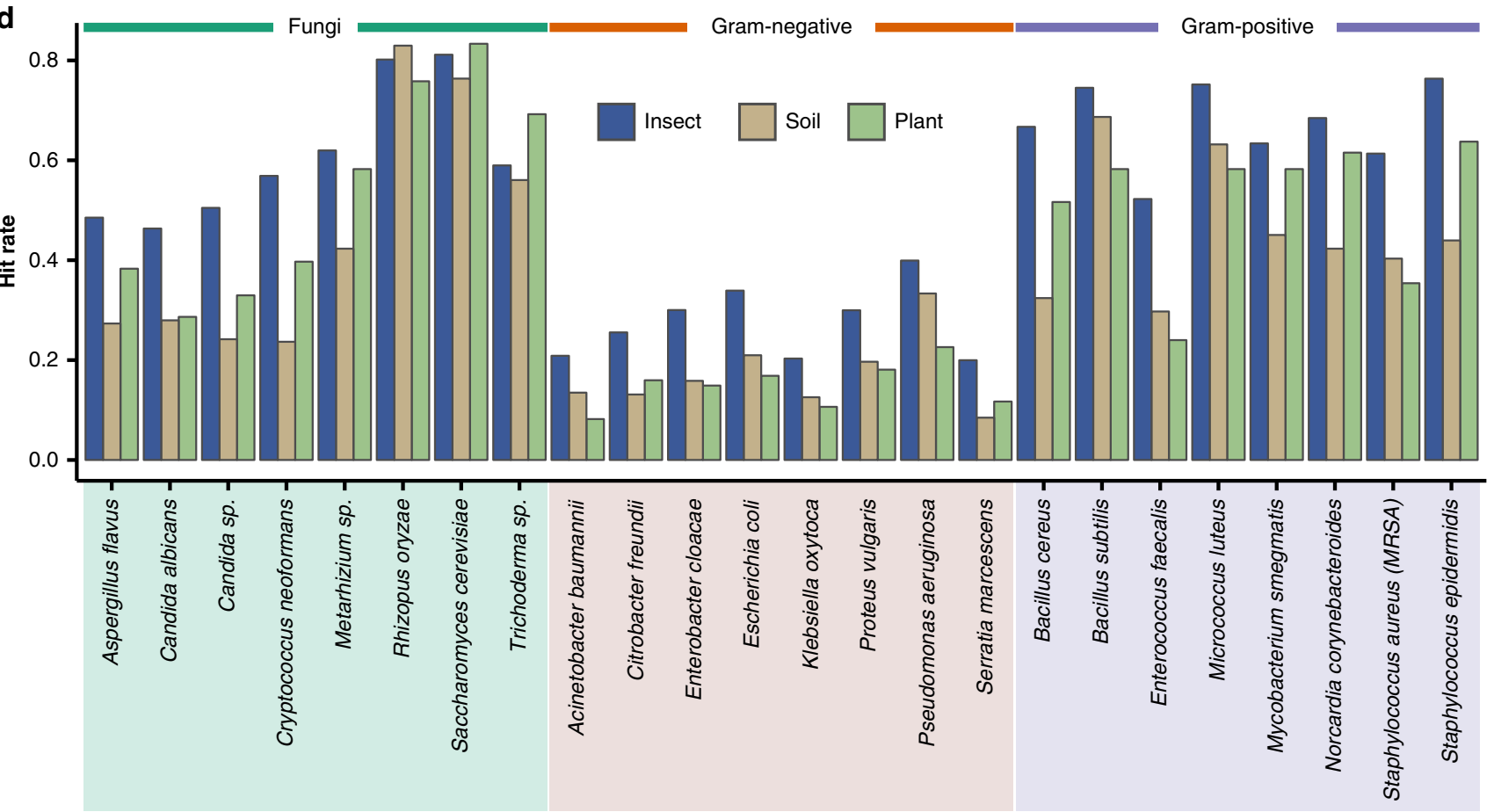

Fig. 3 Bioactivity of insect-associated Streptomyces. a Fungal and $\mathbf{b}$ Gram-negative pathogens are significantly more inhibited by insect-associated isolates compared to soil- and plant-sourced Streptomyces $\left(n=1162,186\right.$, and 178 for insect, soil, and plant, respectively; ${ }^{\star \star \star} p<1 \mathrm{e}-3$; ${ }^{\star \star} p<1 \mathrm{e}-2 ; t$-test, BY correction). c Strains vary in antimicrobial bioactivity by insect host orders $(n=87,69,327,518,94$, and 39 for Blattodea, Coleoptera, Diptera, Hymenoptera, Lepidoptera, and Orthoptera, respectively). a-c: center, median; box, upper and lower quantiles; notches, 95\% confidence; whiskers, 1.5× interquartile range; points, outliers. d Hit rate for insect, soil, and plant strains against individual pathogens ( $n=1162,186$, and 178 for insect, soil, and plant, respectively)

(Fig. 3c). For example, strains isolated from Orthoptera (crickets and grasshoppers; $n=39$ ), Blattodea (termites and cockroaches; $n=87$ ), and Hymenoptera (ants, bees, and wasps; $n=518$ ) had particularly high inhibition against Gram-negative bacteria and had inhibition fractions of $0.25,0.16,0.11$ higher than the average soil isolate, respectively. In challenges against fungi, strains from Blattodea (termites and cockroaches; $n=87$ ) and Lepidoptera (moths and butterflies; $n=94$ ) had particularly effective antimicrobial activity, with inhibition fractions greater than that of the average soil isolate by 0.26 and 0.13 , respectively. Similar trends were seen in Gram-positive assays (Supplementary Figure 1B).

Insect-associated strains have higher bioactivity against these pathogen classes compared to soil Actinobacteria (Fig. 3a-c,
Supplementary Figure 1A-B) and variation of activity between host orders suggests the microbiomes of some insect lineages are better equipped to defend against specific pathogen classes (Fig. 3c, Supplementary Figure 1D-E). Furthermore, insectassociated Streptomyces generally have higher rates of inhibition (i.e., hit rate) against many important clinical pathogens, including Pseudomonas aeruginosa, Acinetobacter baumannii, Candida albicans, and methicillin-resistant Staphylococcus aureus (Fig. 3d). These assays reflect traditional, albeit high-throughput, approaches for antimicrobial screening. Biosynthesis of secondary metabolites is often dependent on many factors not present in the lab, so metabolites from certain environments (e.g., a hostassociated Streptomyces cultured in the absence of environmental cue) may not be produced under these conditions ${ }^{32,33}$. 
a

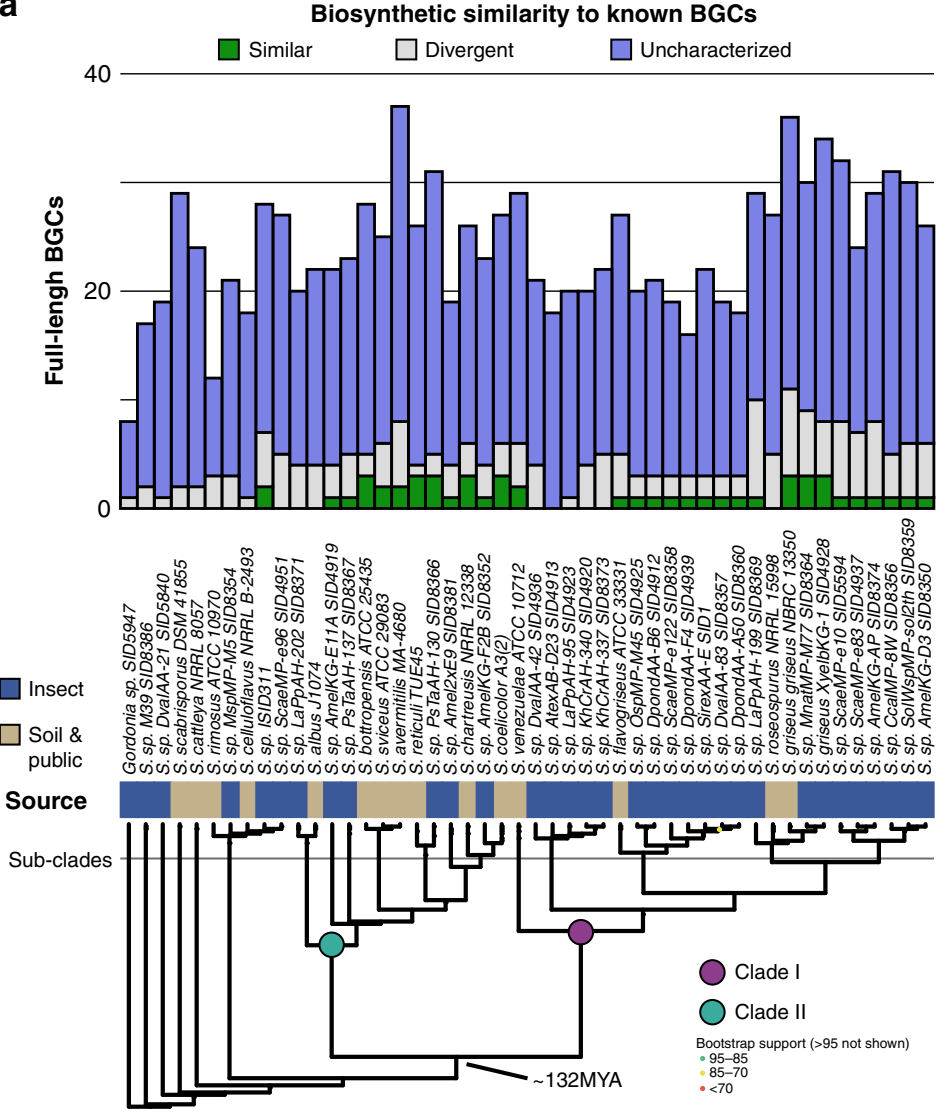

b

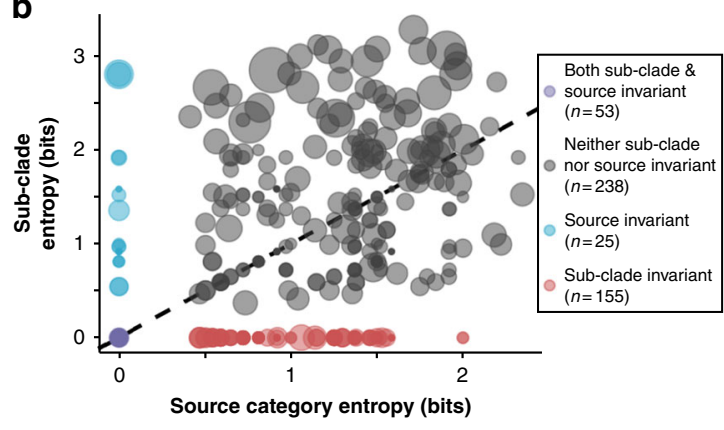

C
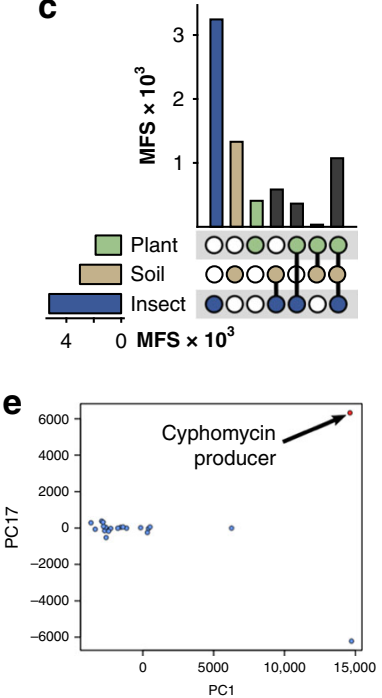

d

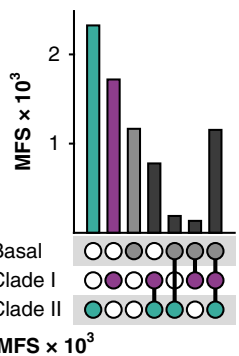

f

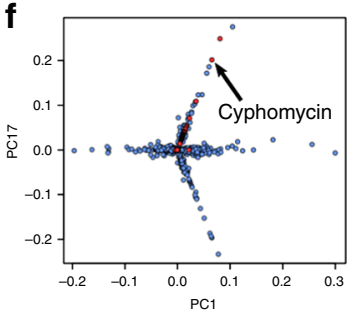

Fig. 4 Ecology and phylogeny influence biosynthetic potential. a A core-genome phylogeny shows evolutionarily distinct lineages of Streptomyces associate with insects (subset shown, see Supplementary Figure 2). BGC similarity to known BGCs highlights the biosynthetic diversity of insect microbiome strains. b Source invariant (blue) and sub-clade invariant (red) BGC families suggest BGC presence is influenced by both source and phylogeny. LC/MS metabolomics revealed MFs that are unique to $\mathbf{c}$ source and $\mathbf{d}$ phylogeny. e PCA of the metabolomes identified an outlier strain and $\mathbf{f}$ MFs that contribute to its uniqueness, including cyphomycin

Nevertheless, significantly higher overall inhibitory activity of insect Streptomyces compared to soil strains suggests insects generally associate with strains with greater antimicrobial potential and thus represent a promising source for antimicrobial discovery.

Biosynthetic potential is shaped by ecology and phylogeny. We next determined the genomic potential of insect-associated Streptomyces as a source of novel natural products. Coregenome phylogenetic studies of 120 strains (69 from insects) show that specific lineages of Streptomyces appear to be associated with insect hosts. Most insect-associated Streptomyces strains cluster together in discrete insect-associated lineages, often separated from soil Streptomyces lineages by millions of years ${ }^{34}$. This is further supported by our 16S rRNA gene phylogeny (Fig. 2). Thus, our findings suggest that Streptomyces from insects occupy unique evolutionary space for natural product discovery (Supplementary Figure 2A, subset shown in Fig. 4a). Through identification and characterization of the 4948 biosynthetic gene cluster (BGC) fragments present in these genomes via anti$\mathrm{SMASH}^{35}$, we show insect-associated Streptomyces harbor vast potential for natural product biosynthesis. BGCs were classified into 2672 families with BiG-SCAP ${ }^{36}$ over $71 \%$ of which were present within only a single genome (Supplementary Figure 2B, Supplementary Data 5). Among BGCs, 31\% (1539) were flanked by at least $0.5 \mathrm{~kb}$ of sequence on either side, indicating the BGC was fully resolved. Notably, the distinct evolutionary lineages of Streptomyces enriched in insect-associated strains harbor much of the uncharacterized biosynthetic potential and have led to the discovery of new molecules (such as cyphomycin; see Fig. 5). Soil and insect Streptomyces had similar full-length BGC abundances in major biosynthetic cluster types and dedicated similar fractions of their genomes to secondary metabolism (11\% and $12 \%$, respectively; Supplementary Figure 2C-E). Uncharacterized BGCs are abundant across Streptomyces. Known BGCs are primarily found within well-studied, soil-derived species such as $S$. griseus and $S$. coelicolor, which may contribute to the issue of compound rediscovery during soil-centered sampling campaigns. The diversity of BGCs with respect to both sub-clade (Fig. 4a, phylogeny) and source indicates that the BGCs present within a Streptomyces genome are influenced by both phylogeny and ecology (Fig. 4b). Many BGC families had a Shannon entropy of zero with respect to their sub-clade, indicating their strong phylogenetic signal is likely related to a vertical evolutionary history. Other BGC families were source invariant, indicating that they are found exclusively within a specific ecological context (e.g., only within insect microbiomes). The influence of both phylogeny and ecology on BGC content further supports that Streptomyces from insect microbiomes represent a unique source of new antimicrobial chemistry. 
a

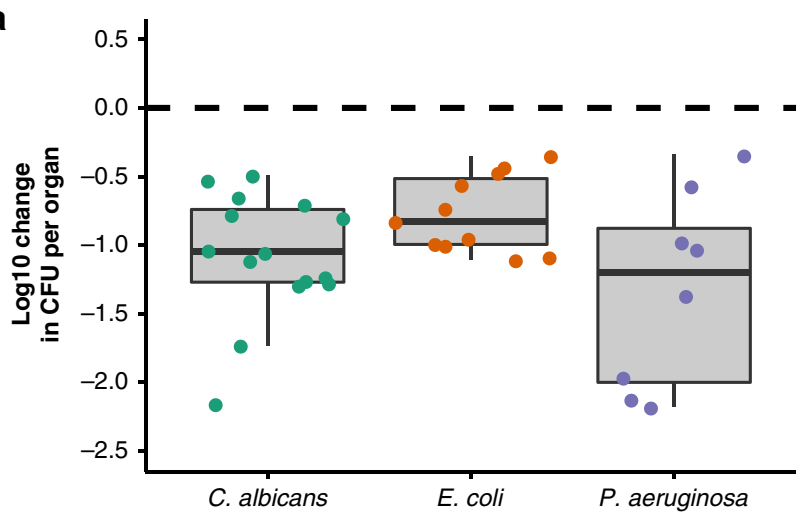

b

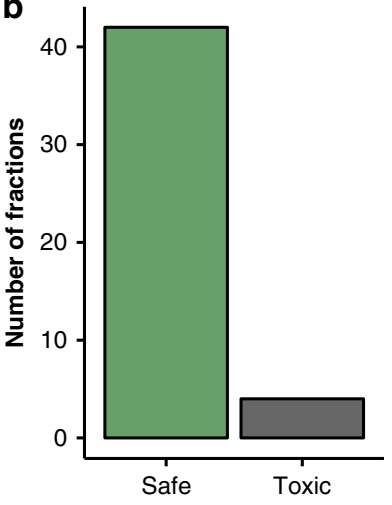

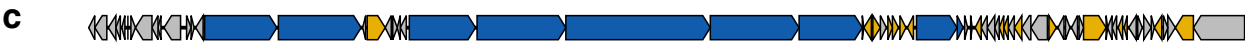
$199 \mathrm{~Kb}$

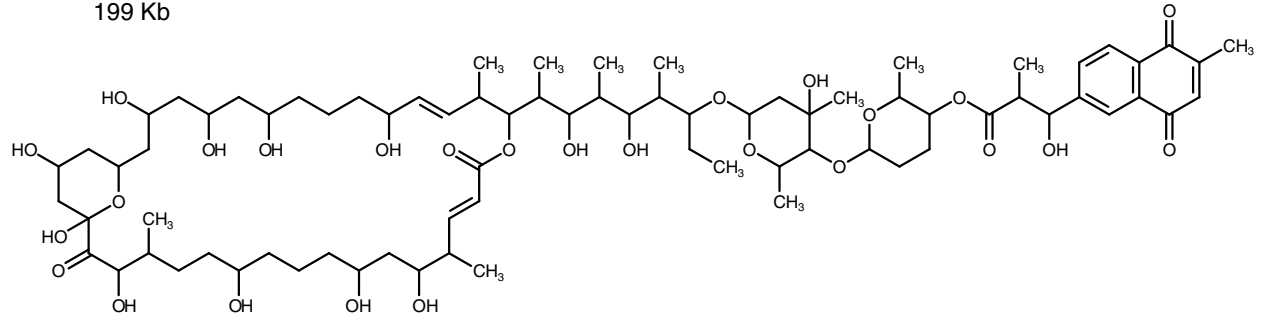
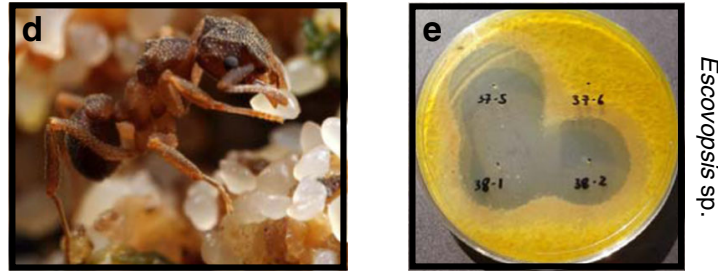

f Strain

Aspergillus fumigatus 11628

Candida glabrata 4720

Candida auris $B 11211$

$\begin{array}{ll}\begin{array}{l}\text { Drug resistance } \\ \text { phenotype }\end{array} & \begin{array}{l}\text { Cyphomycin } \\ \text { MIC }\left(\mu \mathrm{g} \mathrm{mL}^{-1}\right)\end{array} \\ \text { Triazole }(\mathrm{T}) & 0.5 \\ \text { Echinocandin (E) } & 0.5 \\ \text { T, E, Amphotericin B } & 4\end{array}$

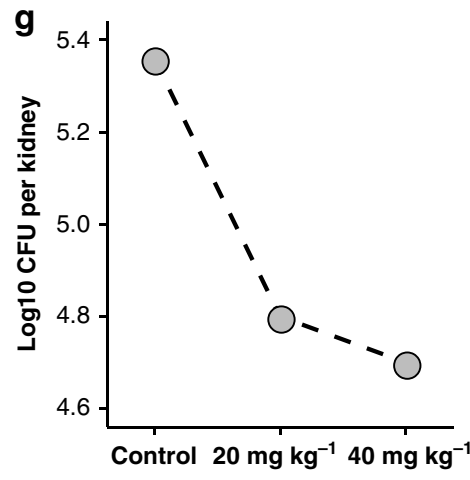

Fig. 5 Insect-associated Streptomyces are a source of active antimicrobials. a Fractionated extracts from insect microbiomes are active in multiple murine models of drug-resistant infection. Less infective burden is seen in intraperitoneally treated mice after $8 \mathrm{~h}$ of infection. Each dot represents a unique fraction in one mouse study. ( $n=15,11$, and 8 for $C$. albicans, E. coli, and P. aeruginosa models, respectively; center, median; box, upper and lower quantiles; whiskers, $1.5 \times$ interquartile range. $\mathbf{b}$ Most fractions from insect microbiomes show no hemolysis in cell-based assays. Safe indicates no toxicity at $>100 \times$ concentration associated with efficacy. c The antifungal cyphomycin is produced by Streptomyces isolated from $\mathbf{d}$ the fungus-growing ant Cyphomyrmex sp. Photo credit: Alexander Wild e Cyphomycin-containing fractions show potency against the ant pathogen Escovopsis sp. (top left, bottom). f Purified cyphomycin exhibits potency against resistant pathogens. $\mathbf{g}$ Mouse candidiasis (C. albicans) models showcase reduced infection and a dose-like response to cyphomycin. Dots indicate individual mice

Ecology and phylogeny influence metabolomic profiles. We also compared the chemical fingerprints of insect-, plant-, and soil-sourced Streptomyces using untargeted liquid chromatography mass spectrometry (LC/MS) metabolomics of 120 strains (69 from insects, same strains as in genomics above). In accordance with genomic predictions of chemical diversity from BGCs, molecular features (MFs) from LC/MS support that metabolome chemical diversity is also heavily influenced by both phylogeny and ecology. Here, our detection of 7727 unique but reproducible (present in all three replicates, but in only 1 of the 120 strains examined) MFs, suggests substantial and specialized chemical diversity in our sampling. Over 4500 (59\%) of MFs were found to be unique to a single strain and $80.2 \%$ were found in four or fewer strains (Supplementary Figure 2F, Supplementary Data 6). Most MFs (3244) are found solely in insect microbiomes within our sampling and 1179 and 2325 are present only in the Clade I and
II evolutionary lineages ${ }^{34}$, respectively, further supporting the influence of both source and phylogeny on chemical diversity (Fig. 4c, d). Principal component analyses (PCA) of these metabolomes identified a Streptomyces sp. ISID311 as metabolic outlier within a group of related Streptomyces (Fig. 4e). A loadings analysis of these principal components identified MFs driving this strain's uniqueness, including the new antifungal cyphomycin (Fig. 4f).

Insect-Streptomyces fractions have potent in vivo activity. To validate that insect microbiomes represent a source of antimicrobials with activity against human pathogens, we conducted in vivo efficacy testing of chemical fractions obtained from different insect Streptomyces strains using murine models for Pseudomonas aeruginosa, Escherichia coli, and Candida albicans 
infections ( $n=8,11$, and 15, respectively; Fig. 5a). Fractions with in vitro activity were subsequently analyzed using UPLC-MS. On average, fractions contained five or fewer compounds, which were compared to Antibase ${ }^{37}$, a database comprised mostly of microbial natural products. Fractions that contained $m / z$ values indicating the presence of unknown/novel molecules and the absence of known molecules (within 5 parts per million) were used in subsequent in vivo mouse studies. Mice treated with fractions from insect-associated Streptomyces had a 1.32 and $0.77 \log$ reduction in infectious burden of the Gram-negative pathogens $P$. aeruginosa or E. coli, respectively, compared to untreated controls. Mice infected with the fungal pathogen $C$. albicans had a $1.07 \log$ reduction in infectious burden when treated with insectStreptomyces fractions. Fractions from insect microbiome Streptomyces show no toxicity in hemolysis assays (concentrations of $50-500 \mu \mathrm{g} \mathrm{mL}^{-1}$ ) for 42 of 46 fractions (91\%; Fig. 5b).

Discovery of cyphomycin, a new antifungal compound. From one such fraction that was positive in mouse studies, we describe the new antifungal compound cyphomycin (Fig. 5c, Supplementary Figures 3 and 4) from a Brazilian Streptomyces (ISID311) isolated from the microbiome of the fungus-growing ant Cyphomyrmex sp. (Fig. 5d). The cyphomycin type 1 polyketide synthase BGC is $199 \mathrm{~kb}$ in length (Fig. 5c; polyketide open reading frames shown in blue, tailoring genes in yellow). It has biosynthetic similarity to the PM100117/8 family of antitumor compounds $^{38}$ (BiG-SCAPE distance of 0.278 ) and structural similarity to the deplelides ${ }^{39}$, yet has key differences in the macrolide core and glycosylation (Supplementary Figures 3 and 4). The Streptomyces that produce PM100117/8 and deplelide have $99.04 \%$ and $98.6 \% 16 \mathrm{~S}$ rRNA gene sequence similarity to ISID311, respectively. The PM100117/8 producing Streptomyces was isolated from a marine polychaete worm (genus Filograna) indicating potential for invertebrate-specialized structures and mechanisms in this class. Purified cyphomycin is active against multidrug-resistant fungal infections both in vitro and in vivo (Fig. 5e-g). Further, cyphomycin shows potent in vitro activity against both the ecologically relevant fungus-growing ant pathogen Escovopsis sp. (Fig. 5e) and the resistant human pathogens Aspergillus fumigatus 11628 (triazole resistance), C. glabrata 4720 (echinocandin resistance), and C. auris B11211 (echinocandin, triazole, and amphotericin B resistance), with low minimum inhibitory concentrations (MICs) in vitro (Fig. 5f). Activity against fungi with resistance mechanisms to all three clinically used classes of antifungals indicates that further study exploring cyphomycin's mechanism of action and resistance is warranted. In a neutropenic mouse disseminated candidiasis model $^{40}$, infective burden was $5.38 \pm 0.04 \log 10$ CFU per kidney for fluconazole $\left(4 \mathrm{mg} \mathrm{kg}^{-1}\right), 5.2 \pm 0.08$ for amphotericin B ( $1 \mathrm{mg}$ $\left.\mathrm{kg}^{-1}\right), 4.8 \pm 0.03$ for micafungin $\left(4 \mathrm{mg} \mathrm{kg}^{-1}\right)$, and $6.78 \pm 0.02$ for untreated controls (all $n=3$ ). It is important to note that these doses produce the same plasma drug exposure seen in humans using standard dosing regimens ${ }^{41}$. In a single-dose study of cyphomycin in the same model, cyphomycin exhibited an in vivo dose-response with 0.56 and $0.66 \mathrm{log}$ reduction of infectious burden compared to the start of therapy when treated with 20 and $40 \mathrm{mg} \mathrm{kg}^{-1}$ cyphomycin, respectively (Fig. 5g), demonstrating cyphomycin's potential for treating clinically relevant pathogens in this industry-standard model of Candida infection ${ }^{42}$.

\section{Discussion}

Through our systematic assessment, we show insect microbiomes present a promising source of novel natural products. Our application of genomics, metabolomics, and ecologically optimized bioassays facilitates rapid screening of strains to explore their untapped chemical diversity. Although primarily thought of as soil microbes, we show Streptomyces from phylogenetically distinct lineages commonly form associations with diverse insect hosts. The unique chemical defenses of insect Streptomyces, such as mycangimycin ${ }^{23}$ and sceliphrolactam ${ }^{27}$, and other insectassociated Actinobacteria, such as dentigerumycin ${ }^{19}$ and selvamicin $^{21}$, have been a fruitful discovery resource in the recent past. Inhibition of Gram-negative and fungal human pathogens (Fig. $3 \mathrm{a}-\mathrm{c}$ ) highlights the value of insect-associated Streptomyces as a source of bioactive molecules. Furthermore, these strains exhibit higher levels of inhibition than strains isolated from traditional sources (i.e., soil) that primarily result in the rediscovery of known compounds ${ }^{43}$. Genomic characterization of the biosynthetic potential of these strains and the metabolomic characterization of their produced metabolites highlight the unique chemical diversity of Streptomyces from insect microbiomes. Cyphomycin is an example of new chemistry from this innovative source. Importantly, the fractions discovered though in vitro and in silico screening retain high efficacy in mouse models of C. albicans, E. coli, and P. aeruginosa infections, and exhibit low toxicity in hemolysis assays (Fig. $5 \mathrm{a}, \mathrm{b}$ ). The unique ecological and evolutionary pressures on the chemical phenotypes of insect microbiomes may have further application in conservation, agriculture, and ecosystem health.

Insect microbiomes appear a particularly valuable source of antimicrobials for treating fungal diseases. High mortality rates and widespread emergence of resistance to many or all known antifungals have made invasive fungal infections a worldwide health burden ${ }^{44}$. The few effective antifungal therapeutics are often plagued with high toxicity and off-target effects and have done little to reduce the high mortality rates of multidrugresistant fungal disease ${ }^{44}$. Streptomyces from insect microbiomes represent a prolific source of antifungal natural products and we show that insect strains exhibit significantly greater activity against fungi than soil Streptomyces (Fig. 3a). Further, we present that cyphomycin, a new molecule isolated from a fungus-growing ant microbiome, is active against multidrug resistant fungal pathogens and demonstrates in vivo efficacy in a commonly utilized infection model for PK/PD studies and FDA applications (Fig. 5f, g). Compared to existing FDA-approved antifungal agents, cyphomycin's $0.25 \mu \mathrm{g} \mathrm{mL}^{-1}$ in vitro MIC against $C$. albicans $\mathrm{K} 1$ is similar to both amphotericin $\mathrm{B}$ and fluconazole ( 0.25 and $0.5 \mu \mathrm{g} \mathrm{mL}^{-1}$, respectively). It is important to note that the deplelides are not described as antifungals, but rather antitumor molecules. Further, we see no evidence of toxicity in mouse studies of cyphomycin and animals exhibited no observed physical or behavioral changes, suggesting that the insect-Streptomyces cyphomycin is a more specific molecule than the soilderived deplelides that are generally toxic to eukaryotes. Together, activity against multidrug-resistant fungi in vitro coupled with high efficacy in in vivo mouse models of infection highlight cyphomycin's potential as a drug lead to treat multidrug resistant fungal infections (Fig. 5f, g).

Antimicrobials developed from soil Streptomyces are the foundation of modern medicine and have saved countless lives. Widespread resistance to these compounds, in combination with the apparent exhaustion of soil Streptomyces as a source of new antimicrobials, represents an alarming health crisis-the rate of antimicrobial resistance continues to far outpace the discovery of novel antimicrobial natural products $2,14,45$. The promise of insect-associated Streptomyces as a new source of antimicrobials has the potential to reinvigorate the stagnated antibacterial and antifungal discovery pipelines. This source has potential farreaching applications stemming from their ecological roles mediating pathogen dynamics associated with their insect hosts. Insects, through evolution, are predicted to have undergone 
millions of years of continual bioprospecting for active, defensive molecules; pathogen pressure selects for association with Streptomyces strains that produce efficacious antimicrobials. Furthermore, insect symbionts are uniquely suited to medicinal discovery, as their host associations appear to enrich for compounds with low toxicity to animals. Our validation of Streptomyces from insect microbiomes as a rich source of bioactive natural products demonstrates the extensive opportunities for antimicrobial discovery within the vast chemical diversity of these microbial communities.

\section{Methods}

Host collection. Host-associated strains were obtained from seven field collections (Florida, Hawaii, Alaska, New Mexico, Wisconsin, California, Brazil) from 2014 to 2016, with various Currie lab archival strains (Supplementary Data 1). Each host was collected using sterile forceps and deposited into a pre-sterilized, pre-barcoded container. Field collections focused heavily on insects that were not in direct contact with soil to avoid the possibility of soil contamination in subsequent surface isolation. Metadata recorded at each field site included: researcher information, date, location, GPS coordinates, micro and macro environment, host description, as well as photographs of each field-site. All specimens were assigned a unique host-identification number (HID) and stored at $4^{\circ} \mathrm{C}$.

\section{Processing and bacterial isolation. All hosts are photographed via dissecting} scope and cataloged by HID.

Insect specimens were processed based on host integrity. If the sample was large enough and completely intact it was processed for external and internal microbial isolates. Large samples were also processed by particle method, using a sterilized surgical scalpel to remove portions of each specimen and placing each piece on an agar plate. If small, degraded or compromised, samples were processed using a combination method: the same procedure as the internal isolation without surface sterilization. External isolation involves transferring host specimen into a $1.5 \mathrm{~mL}$ microcentrifuge tube, adding $125^{*} x$ ( $x=$ number of plates) $\mu \mathrm{L}$ phosphate-buffered saline (PBS), vortexing gently at $50 \%$ speed for $10 \mathrm{~s}$, and transferring $100 \mu \mathrm{L}$ to various media. To select for Actinobacteria, humic acid Agar (HV $)^{46}$ and selective chitin media ${ }^{47}$ with $20 \mathrm{~mL} / 1 \mathrm{~L}$ nystatin, and $10 \mathrm{~mL} / 1 \mathrm{~L}$ cycloheximide added to select against fungal isolates were used. After plating for external isolates, a sterilization wash is preformed to isolate internal microbes. The same microcentrifuge tube from the external was filled with $1 \mathrm{~mL}$ of $70 \%$ ethanol and gently mixed by inversion for $1 \mathrm{~min}$. Ethanol waste was removed and $1 \mathrm{~mL}$ of $1 \%$ bleach with $0.1 \%$ tween 20 solution was added and mixed gently for $30 \mathrm{~s}$ by inversion. Supernatant was removed and host specimen was rinsed $3 \times$ using $1 \mathrm{~mL}$ PBS buffer for $10 \mathrm{~s}$. After external sterilization, $125^{*} x$ ( $x=$ number of plates) $\mu \mathrm{L}$ of PBS was added to the tube. The specimen was then ground-up using a sterile pestle inside the tube. Using a wide bore $200 \mu \mathrm{L}$ tip, $100 \mu \mathrm{L}$ of slurry was transferred onto a pre-labeled media plate (HV \& chitin) and spread evenly. The last $100 \mu \mathrm{L}$ was pipetted into a DNA voucher containing $900 \mu \mathrm{L}$ of $95 \%$ ethanol for storage.

Plant tissue was vortexed in PBS and $100 \mu \mathrm{L}$ plated. Remaining tissue was then surface sterilized, crushed, and plated similarly. Particle plates were generated for some plants, where we plant tissue was placed directly on plates. The same selective protocols as above were used.

Soil was treated similarly by re-suspending $1 \mathrm{~g}$ into $1 \mathrm{~mL}$ of PBS, followed by a $1 \mathrm{e}-5$ serial dilution on chitin and HV. Colonies were then picked.

For all sources, $\mathrm{HV}$ and chitin isolation plates were incubated aerobically at room temperature $\left(28^{\circ} \mathrm{C}\right)$ and checked for bacterial growth at $14 \mathrm{~d}, 30 \mathrm{~d}$, and $90 \mathrm{~d}$. Colonies exhibiting characteristic Actinobacterial morphology ${ }^{48}$ were assigned a strain identification number before isolation onto fresh HV or chitin media and incubation at $28^{\circ} \mathrm{C}$.

$16 S$ sequencing and phylogenetic placement. Genomic DNA was extracted from isolates using the Powersoil DNA isolation kit according to manufacturer's specifications (MoBio). Polymerase chain reaction (PCR) was performed using the universal bacterial primer set 27 F (5'-AGA GTT TGA TCM TGG CTC AG-3') and $1496 \mathrm{R}\left(5^{\prime}\right.$-CGG TTA CCT TGT TAC GAC TT-3'), of hypervariable regions V1-V9. PCR was performed in a standard $25 \mu \mathrm{L}$ reaction with $1 \mu \mathrm{L}$ DNA template (20 ng $\mu \mathrm{L}^{-1}$ ), $12.5 \mu \mathrm{L}$ EconoTaq (Lucigen corporation), $1 \mu \mathrm{L}$ combined $10 \mu \mathrm{M}$ primers, and $12.5 \mu \mathrm{L}$ water. Initial denaturation for $3 \mathrm{~min}$ at $95^{\circ} \mathrm{C}$ was followed by $3 \mathrm{~min}$ annealing at $58^{\circ} \mathrm{C}$ followed by 35 cycles of $10 \mathrm{~s}$ at $96^{\circ} \mathrm{C}$ and $2 \mathrm{~min}$ at $72{ }^{\circ} \mathrm{C}$, and a post-cycle extension at $72{ }^{\circ} \mathrm{C}$ for $7 \mathrm{~min}$. Amplicons were confirmed on $1.2 \%$ agarose electrophoresis gel prior to cleanup wth Wizard SV Gel and PCR system (Promega). Big Dye sequencing reaction was then performed followed by a secondary clean-up prior to submission to UW Biotech for analysis (University of Wisconsin-Madison). 16S sequences were searched with blastn against a database of representative genomes from each clade in the Streptomyces phylogeny (see Genome sequencing and Core-genome phylogeny below). Hits with the best bit score were assigned to that clade. Within clade hits $16 \mathrm{~S}$ were then aligned with MAFFT v7.245 49 and treed with FastTree $2^{50}$ under the GTR substitution model.
Inhibition bioassays and scoring. Isolates were inoculated along the center of wells. Each well contained $3 \mathrm{~mL}$ of yeast peptone mannitol (YPM) agar (2 g yeast extract, $2 \mathrm{~g}$ peptone, $4 \mathrm{~g}$ mannitol, $15 \mathrm{~g}$ agar, $1 \mathrm{~L} \mathrm{H}_{2} \mathrm{O}$ ). Actinobacteria were incubated at $28{ }^{\circ} \mathrm{C}$ for $5 \mathrm{~d}$ prior to the addition of the test pathogens. For fungal pathogens, spore stocks of each fungal strain were diluted 1:10 (Supplementary Data 3 ). For bacterial and yeast pathogens $3 \mathrm{~mL}$ of broth containing the microorganism was inoculated into sterile $14 \mathrm{~mL}$ tubes with Luria-Bertani (LB) or yeast peptone dextrose (YPD), respectively. Cultures were shaken overnight at $28^{\circ} \mathrm{C}$ and diluted 1:10 (Supplementary Data 3). Diluted cultures were used to inoculate $3 \mu \mathrm{L}$ in the center of the well and the non-pathogen controls. Plates were maintained at $28^{\circ} \mathrm{C}$ for $7 \mathrm{~d}$. Inhibition was scored in binary, as 0 (no inhibition) or 1 (inhibition). For a subset of isolates, experimental wells were assigned a rating from 0 to 3 depending on the level of inhibition (0-no inhibition, 1 -slight inhibition, 2 -presence of a zone of inhibition, 3-complete inhibition).

Inhibition fraction was determined by taking the average inhibition of Strain $X$ vs. Pathogen $Y$ to account for variance if multiple $X$ by $Y$ challenges were run. This was done for all pathogens against $X$. Gram-positive, gram-negative, and fungal averages were then computed to find the inhibition fraction for $X$. Strains were grouped by source and $p$-values were calculated by $T$-test with Benjamini/ Yekutieli correction ${ }^{51}$. Fuzzy clustering was used to group inhibitory profiles using Mfuzz 52

Genome sequencing and assembly. 120 strains were selected for whole genome sequencing based on 16S rRNA gene sequence so to span the Streptomyces phylogeny, including outgroups. Cultures were grown in rich medium supplemented with $0.5 \%$ glycine and cells were harvested by centrifugation. Cells were washed with $10.3 \%$ sucrose, resuspended in lysozyme solution $\left(3 \mathrm{mg} \mathrm{mL}^{-1}\right.$ lysozyme, Sigma, in $0.3 \mathrm{M}$ sucrose, $25 \mathrm{mM}$ Tris $\mathrm{pH} 8,25 \mathrm{mM}$ EDTA pH 8), and incubated at $37^{\circ} \mathrm{C}$ for $30 \mathrm{~min}$. Proteinase $\mathrm{K}$ (Thermo Fisher; $20 \mathrm{mg} \mathrm{mL}^{-1}$ ) was added before incubation for $15 \mathrm{~min}$ at $42{ }^{\circ} \mathrm{C}$. Cells were lysed by adding $2 \%$ SDS and rocking for 5 min until lysis was complete. Neutral phenol and chloroform were added, and tubes were gently shaken until uniformly white. After centrifugation, the top layer was transferred to $3 \mathrm{M}$ sodium acetate $\mathrm{pH} 6$ and isopropanol. Tubes were gently mixed until DNA appeared. DNA was pelleted, supernatant was removed, and the pellet was resuspended in TE with $0.2 \mathrm{mg} \mathrm{mL}^{-1} \mathrm{RNaseA}$. Tubes were incubated $15 \mathrm{~min}$ at $28^{\circ} \mathrm{C}$ before adding $5 \mathrm{M} \mathrm{NaCl}$ and $\mathrm{CTAB} / \mathrm{NaCl}$ solution. Tubes were incubated for $10 \mathrm{~min}$ at $55^{\circ} \mathrm{C}$ and cooled to $28^{\circ} \mathrm{C}$. $\mathrm{CHCl}_{3}$ was added, tubes were gently shaken, and spun for $10 \mathrm{~min}$ at $28^{\circ} \mathrm{C}$. The top layer was transferred to a new tube and extracted again with phenol and chloroform, followed by extraction with chloroform and precipitation with $3 \mathrm{M}$ sodium acetate $\mathrm{pH} 6$ and isopropanol. The pellet was washed in $70 \%$ ethanol and resuspended in water. DNA was quantified, checked for purity, and run on a gel to verify high molecular weight. Genomic DNA libraries for Illumina MiSeq $2 \times 300$ bp paired-end sequencing were prepared by the University of Wisconsin-Madison Biotechnology Center (TruSeq). Reads were corrected with MUSKET v1.1 ${ }^{53}$, paired-ends were merged with FLASH v1.2.754, and assembled with SPAdes v3.11.0 $0^{55}$.

Core-genome phylogeny. A genome-based, multilocus phylogeny was generated using 93 TIGRFAM proteins in the core bacterial protein set (GenProp0799; http:// www.jcvi.org/cgi-bin/genome-properties/GenomePropDefinition.cgi? prop_acc=GenProp0799). Genes were called with prodigal v2.6.0 $0^{56}$ and GenProp0799 profile Hidden Markov Models were used to search each genome. HMMER v3.1b $2^{57}$ was used to identify protein sequences for each protein family. Each family was then aligned using MAFFT v7.245 ${ }^{49}$. Alignments were then converted to codon alignments and concatenated. The multi-locus phylogeny was generated using RAxML v8.1.24 $4^{58}$ under the GTRgamma substitution model with 100 rapid bootstraps.

Analysis of biosynthetic gene clusters. BGCs were identified within each genome with antiSMASH v4.0 ${ }^{35}$. BGCs were determined to be full-length if $0.5 \mathrm{~kb}$ of flanking sequence existed between cluster boundaries and the end of the contig. BGCs were used to identify BGC groups via BiG-SCAPE (https://git.wageningenur. $\mathrm{nl} /$ medema-group/BiG-SCAPE/) under --hybrid and --mode glocal settings at a distance cutoff of 0.5 . BGCs from our dataset were combined with all available BGCs from MIBiG v1.3 ${ }^{59}$ and again groups were called in BiG-SCAPE. Distances $<0.5$ were called similar, between 0.5 and 0.75 divergent, and over 0.75 uncharacterized. Shannon entropy with respect to phylogeny, strain source (e.g., insectassociated, soil, plant), and insect-host order were calculated for BGC groups.

Untargeted LC/MS. Streptomyces were cultured on YPM agar media and grown for up to 14 days or until sporulation. Two $8 \mathrm{~mm}$ diameter cores were sampled directly and extracted with $2 \mathrm{~mL}$ of $\mathrm{MeOH}$ for $30 \mathrm{~min}$. Extracts were transferred to new vials and vacuum dried. Extracts were dissolved in $100 \mu \mathrm{L}$ of $\mathrm{MeOH}$, followed by $1 \mathrm{~mL}$ of Milli-Q water. Solid phase extraction (SPE) was conducted using Biotage: EVOLUTE ABN ( $25 \mathrm{mg}, 1 \mathrm{~mL})$. Samples were loaded following con ditioning with $\mathrm{MeOH}$ and then Milli-Q water. Extracts were washed with Milli-Q water to remove media components and primary metabolites and then eluted with $\mathrm{MeOH}$ into LC/MS certified vials. Mass spectra were collected using a Bruker MaXis ESI-Q-TOF mass spectrometer. Liquid chromatography was conducted 
using a Waters Acquity UPLC on a RP-C18 column (Phenomenex Kinetex $2.6 \mu \mathrm{m}$, $2.1 \mathrm{~mm} \times 100 \mathrm{~mm}$ ). Both instruments were operated using Bruker Hystar software. A linear $\mathrm{MeOH} / \mathrm{H}_{2} \mathrm{O}$ (0.1\% formic acid) gradient was used beginning at $10 \% / 90 \%$ and reaching $97 \% / 3 \%$ in $12 \mathrm{~min}$ and held for $3.5 \mathrm{~min}$. The column was set to initial conditions in $0.5 \mathrm{~min}$ and re-equilibrated for $3.5 \mathrm{~min}$ before subsequent runs. The flow rate was $0.3 \mathrm{~mL} \mathrm{~min}{ }^{-1}$. Full-scan mass spectra $(\mathrm{m} / z$ 150-1550) was collected in positive ESI mode. The following parameters were used: capillary, $4500 \mathrm{~V}$; nebulizer, 1.2 bar; dry gas flow rate, $8.0 \mathrm{~L} \mathrm{~min}^{-1}$; dry gas temperature, $205^{\circ} \mathrm{C}$; scan rate, $2 \mathrm{~Hz}$. Automatic internal calibration was conducted after each run by introducing Tune Mix (Agilent, ESI-L low concentration) through a divert valve during re-equilibration. Bucket tables from LC/MS were generated in Bruker Profile Analysis 2.1 with Molecular features identified as follows: $\mathrm{S} / \mathrm{N}$ threshold, 5; correlation coefficient threshold, 0.7 ; minimum compound length, 10 spectra; smoothing width, 1; bucketing basis, $M+H$. Buckets were generated from LC/MS traces between 120 and $840 \mathrm{~s}$ and for $\mathrm{m} / z$ ratios between 150 and 1500. Advanced bucketing was used with $\Delta \mathrm{RT}=20 \mathrm{~s}$ and $\Delta m / z=20 \mathrm{mDa}$. Buckets were normalized to the sum of buckets values in the analysis. Mass to charge ratios were manually cross-referenced with Antibase ${ }^{37}$ within 5 parts per million of $\mathrm{M}, \mathrm{M}+\mathrm{H}$, and $\mathrm{M}+\mathrm{Na}$ adduct states.

Hemolysis assay. Assays were performed in 384-well plates using sheep blood ( $0.1 \%$ triton as the positive control). Sheep's blood (Ward's Science) was washed with PBS and diluted to a concentration of $6 \times 10^{7}$ red blood cells per mL. A volume of $50 \mu \mathrm{L}$ of blood was incubated with compound for $1 \mathrm{~h}$, and subsequently pelleted at $4000 \mathrm{rpm}$ for $10 \mathrm{~min}$. Thirty microliters of supernatant were transferred to a clear plate and OD570 was read. An increase in OD indicated the red blood cell lysis and hemolytic activity.

Mouse studies. All mouse experiments and protocols received ethical approval from the University of Wisconsin Institutional Animal Care and Use Committee.

Candida model. Six-week-old, specific-pathogen-free, female ICR/Swiss mice weighing 23-27g were used for all studies (Harlan Sprague-Dawley, Indianapolis, IN). Animals were maintained in accordance with the criteria of the Association for Assessment and Accreditation of Laboratory Animal Care. All animal studies were approved by the Animal Research Committee of the William S. Middleton Memorial Veterans Hospital. Mice were rendered neutropenic (neutrophils, 100 per $\mathrm{mm}^{3}$ ) by injection with cyclophosphamide (Mead Johnson Pharmaceuticals, Evansville, IN) subcutaneously 4 days $\left(150 \mathrm{mg} \mathrm{kg}^{-1}\right)$ and 1 day $\left(100 \mathrm{mg} \mathrm{kg}^{-1}\right)$ before infection and 2 days after infection $\left(100 \mathrm{mg} \mathrm{kg}^{-1}\right)$. Previous studies have shown neutropenia (neutrophils, 100 per $\mathrm{mm}^{3}$ ) in this model for the 96-h study period $^{42}$. Organisms were subcultured on SDA $24 \mathrm{~h}$ prior to infection. Inoculum was prepared by placing three to five colonies into $5 \mathrm{~mL}$ of sterile pyrogen-free $0.9 \%$ saline warmed to $35^{\circ} \mathrm{C}$. The final inoculum was adjusted to a 0.6 transmittance at $530 \mathrm{~nm}$. Fungal counts of the inoculum determined by viable counts of $C$. albicans on SDA were $6.29 \pm 0.03,6.15 \pm 0.10$, and $6.30 \pm 0.07 \log 10 \mathrm{CFU} \mathrm{mL}{ }^{-1}$, respectively. Disseminated infection with the Candida was achieved by injection of $0.1 \mathrm{~mL}$ of inoculum via the lateral tail vein $2 \mathrm{~h}$ prior to the start of drug therapy. Treatment period was $8 \mathrm{~h}$. Animals were sacrificed by $\mathrm{CO}_{2}$ asphyxiation. Kidneys of each mouse were removed and placed in sterile $0.9 \%$ saline at $4{ }^{\circ} \mathrm{C}$. The homogenate was serially diluted and aliquots were plated on SDA for viable fungal colony counts after incubation for $24 \mathrm{~h}$ at $35^{\circ} \mathrm{C}$. The lower limit of detection was $100 \mathrm{CFU} \mathrm{mL} \mathrm{mL}^{-1}$. Results were expressed as the mean number of CFU per kidney for three mice. No-treatment and zero-hour controls were included in all experiments.

Mouse bacterial thigh infection model. Animals for the present studies were maintained in accordance with the criteria of the Association for Assessment and Accreditation of Laboratory Animal Care. All animal studies were approved by the Animal Research Committee of the William S. Middleton Memorial VA Hospital.

Six-week-old, specific-pathogen-free, female ICR/Swiss mice weighing 23-27 g were used for all studies (Harlan Sprague-Dawley, Indianapolis, IN). Mice were rendered neutropenic (neutrophil count, $<100 \mathrm{~mm}^{-3}$ ) by injecting them with cyclophosphamide (Mead Johnson Pharmaceuticals, Evansville, IN) subcutaneously 4 days $\left(150 \mathrm{mg} \mathrm{kg}^{-1}\right)$ and 1 day $\left(100 \mathrm{mg} \mathrm{kg}^{-1}\right)$ before thigh infection. Previous studies have shown that this regimen produces neutropenia in this model for 5 days ${ }^{40}$. Broth cultures of freshly plated bacteria were grown overnight to logarithmic phase to an absorbance at $580 \mathrm{~nm}$ of 0.3 (Spectronic 88; Bausch and Lomb, Rochester, NY). After 1:10 dilution into fresh Mueller-Hinton broth, the bacterial counts of the inoculum ranged from $10^{7.0}$ to $10^{7.4} \mathrm{CFU} \mathrm{mL}^{-1}$. Thigh infections with each of the isolates were produced by injection of $0.1 \mathrm{~mL}$ of inoculum into the thighs of isoflurane-anesthetized mice. Antibacterial therapy was initiated $2 \mathrm{~h}$ after the infection procedure. After $8 \mathrm{~h}$, the animals were euthanized, and the thighs were aseptically removed, homogenized, and plated for determination of the number of CFU. No-treatment controls were included in all experiments.

In vivo murine studies. To analyze fractions as candidates for in vivo study, we used Core-shell technology UPLC columns which provide extensive sensitivity and dynamic range for small molecules ${ }^{60}$ (Fig. 5a). The threshold in terms of accuracy was set at 3-5 ppm, well beyond the RMSD accuracy of a Bruker MaXis $4 \mathrm{G}$ (specifications of better than 1 PPM). Additionally, NMR data for each fraction were acquired using a $1.7 \mathrm{~mm}$ cryoprobe, the most sensitive NMR system for $1 \mathrm{H}$ analysis. Prior to in vivo testing, samples were analyzed by NMR and LCMS to ensure characteristics of each sample matched to the original sample that exhibited in vitro activity. Since ELSD data were used to quantify each fraction, we were able to account for the mass of fraction during preparation of the LCMS sample. Acquisitions were performed such that ion counts of $10^{6}$ or greater were observed for the highest abundance ions, which facilitated detection of minor components. While there is a possibility of a known compound that does not ionize by ESI, studies indicate that $93 \%$ of microbial natural products ionize by positive ESI ${ }^{61}$

LCT-ToF was used (as in Nielsen et al. ${ }^{61}$ where $93 \%$ ionization of microbial natural products was reported). In addition, a Bruker MaXis 4G with an Acquity UPLC front end and core shell columns was used to maximize sensitivity for ESIMS of small molecules (dynamic range of 4.7 orders of magnitude). As such, ion counts in the millions maintain accuracy and appropriate peak shape. Low abundance ions (below 100 counts) can also be detected (noise is $\sim 30-50$ counts). Thus, with the increased accuracy and range of our instrument, the $93 \%$ estimate of microbial natural products from Nielsen et al. is a lower bound. Some lipids (e.g., those without carboxylic acid groups) and terpenes (e.g., those with few oxygens) ionize poorly and may be missed by ESI-MS, but within actinomycetes, we encounter few terpenes being produced under laboratory conditions.

Mice were treated $2 \mathrm{~h}$ after infection and sampled 6-8 $\mathrm{h}$ after treatment. Bacteria were grown in three different media (A media, ISP-2, YPM, and AMedium; $100 \mathrm{~mL}$ each) with Diaion HP20 (7\% by weight) and shaken at $200 \mathrm{rpm}$ at $28{ }^{\circ} \mathrm{C}$ for 7 days. Filtered HP20 was washed with water and extracted with acetone. The acetone extracts from the three media were combined and followed by solid phase extraction using $\mathrm{ENV}^{+}$columns to generate four fractions. These four fractions were further purified by HPLC to generate 80 fractions for each strain in a 96-well plate. High-throughput screening was used to evaluate the antimicrobial activity of these fractions. Dereplication based on $1.7 \mathrm{~mm}$ NMR and HRMS was used to select promising hits. Select strains were re-grown in the large scale in the three media, and followed the same processor mentioned before to generate the fractions containing potential novel active compounds. These fractions were formulated and tested in vivo activity (Fig. 5a).

In vitro MIC susceptibility testing. MICs of cyphomycin for the Candida isolates were determined using a broth microdilution method in accordance with the guidelines presented in Clinical and Laboratory Standards Institute (CLSI) document M27-A3 for Candida and M38-A2 for Aspergillus ${ }^{40,42}$. MIC values of cyphomycin were defined as the lowest concentration at which a prominent decrease in growth turbidity (i.e., $50 \%$ reduction in growth determined spectrophotometrically) relative to the turbidity of the compound-free control at $600 \mathrm{~nm}$ was observed. Median MIC from replicate assays is reported.

Cyphomycin-culturing and isolation. Streptomyces ISID311 was grown in Amedium broth $(20 \mathrm{~g}$ soluble starch, $10 \mathrm{~g}$ glucose, $5 \mathrm{~g}$ peptone, $5 \mathrm{~g}$ yeast extract, $5 \mathrm{~g}$ $\mathrm{CaCO}_{3}$ per liter) using Fernbach flasks [5× (1 L of medium in $2.8 \mathrm{~L}+70 \mathrm{~g}$ of HP20)] and shaken for 7 days at $28^{\circ} \mathrm{C}$ and $200 \mathrm{rpm}$. The HP20 was filtered and washed with distillated water and soaked with acetone. Organic solvent was filtered, vacuum dried, and partitioned with ethyl acetate/water. Organic phase was separated and dried to give the crude extract $(2.3044 \mathrm{~g})$. Extract was purified by SPE-C18 $(55 \mu \mathrm{m}, 20 \mathrm{~g})$ using the following gradient: $200 \mathrm{~mL}\left(20 \% \mathrm{MeOH}-\mathrm{H}_{2} \mathrm{O}\right.$, A1: $72.8 \mathrm{mg}) ; 200 \mathrm{~mL}$ (40\% MeOH- $\left.\mathrm{H}_{2} \mathrm{O}, \mathbf{A 2}: 152.5 \mathrm{mg}\right) ; 200 \mathrm{~mL}(60 \% \mathrm{MeOH}-$ $\mathrm{H}_{2} \mathrm{O}$, A3: $\left.132.3 \mathrm{mg}\right)$; and $200 \mathrm{~mL}(100 \% \mathrm{MeOH}, \mathbf{A 4}: 1.9349 \mathrm{~g})$.

A4 was purified by semi-preparative HPLC using $\mathrm{C}_{18}$ semipreparative column (Phenomenex Luna, $\mathrm{C}_{18}(2), 5 \mu \mathrm{m}, 250 \times 10 \mathrm{~mm}$ ) and the following gradient of $\mathrm{MeOH}$ and $\mathrm{H}_{2} \mathrm{O}$ (containing $0.1 \%$ of acetic acid) at $4 \mathrm{~mL} \mathrm{~min}^{-1}$ : min $1-20$ (linear gradient from $80 \% \mathrm{MeOH}-\mathrm{H}_{2} \mathrm{O}$ to $100 \% \mathrm{MeOH}$ ); min $20-22$ (isocratic flow of $100 \% \mathrm{MeOH}$ ); min $22-22.5$ (linear gradient from $100 \% \mathrm{MeOH}$ to $80 \% \mathrm{MeOH}-$ $\mathrm{H}_{2} \mathrm{O}$ ); and min $22.5-27.5$ (isocratic flow of $80 \% \mathrm{MeOH}-\mathrm{H}_{2} \mathrm{O}$ ) to yield cyphomycin $\left(89.0 \mathrm{mg}, t_{\mathrm{R}}=11.4 \mathrm{~min}\right.$ ).

Cyphomycin-structural determination. The molecular formula of cyphomycin was $\mathrm{C}_{77} \mathrm{H}_{122} \mathrm{O}_{26}$ based on positive ion HRESIMS $\left([\mathrm{M}+\mathrm{H}]^{+} m / z 1463.8282\right.$, err 1.0 $\mathrm{ppm})$. The ${ }^{1} \mathrm{H}$ and ${ }^{13} \mathrm{C}$ NMR spectral data of 2 are shown in Supplementary Figure 3AI. The ${ }^{13} \mathrm{C}$ NMR spectrum showed 77 signals assigned to 12 methyl, 18 methylene, 36 methine, 5 carbonyl carbons, 4 tertiary carbons sp ${ }^{2}$ and 2 quaternary carbon groups by multiplicity-edited $g \mathrm{HSQC}$ experiment. The COSY and HSQCTOCSY spectra revealed connectivity from $\mathrm{H}-2$ to $\mathrm{H}-15$ and $\mathrm{H}-18$ to $\mathrm{H}-43$ (Supplementary Figure 3AF).

Connection of these two spin systems was revealed with the $\mathrm{HMBC}$ correlation of $\mathrm{H}-18\left(\delta_{\mathrm{H}} 2.09\right.$ and 1.33$)$ to $\mathrm{C}-16$ and C-17; $\mathrm{H}-15\left(\delta_{\mathrm{H}} 4.69\right)$ to C-16; and $\mathrm{H}-35$ $\left(\delta_{\mathrm{H}} 5.14\right)$ to C-1. Geometry of the two double bonds of macrolide were determine to be $E$ configured by coupling constants of ${ }^{3} J_{\mathrm{H}-2, \mathrm{H}-3}(15.8 \mathrm{~Hz})$ and ${ }^{3} \mathrm{~J}_{\mathrm{H}-32, \mathrm{H}-33}(15.6$ $\mathrm{Hz}$ ). The positions of methine groups $\mathrm{H}-4, \mathrm{H}-14, \mathrm{H}-34, \mathrm{H}-36, \mathrm{H}-38$ and $\mathrm{H}-40$ were assigned by ${ }^{1} \mathrm{H}^{-1} \mathrm{H}$ COSY correlations to methyl groups $\mathrm{H}-44, \mathrm{H}-45, \mathrm{H}-46, \mathrm{H}-47$, $\mathrm{H}-48$ and $\mathrm{H}-49$, respectively. The methyl group $\mathrm{H}-43$ was assigned as terminal group of side chain by its triplet multiplicity in ${ }^{1} \mathrm{H}$ NMR spectrum and HMBC 
correlations to C-41 and C- 42 . Positions of oxygenated methine and methylene groups in macrolactone moiety were established by HMBC, COSY and HSQCTOCSY correlations, and comparison of NMR data of compounds PM100117/ $8^{38}$. Difference in macrolactone moiety of compound 1 versus PM100117/8 is the additional methyl group $\mathrm{H}-44$ attached to $\mathrm{C}-4$. Other similar macrolactones of 36 members are described in GT-35 and Deplelides A and B 39 .

The presence of two sugar units was evidenced by signal of ${ }^{1} \mathrm{H}$ and ${ }^{13} \mathrm{C}$ NMR of two anomeric protons and carbons at $\delta_{\mathrm{H}} 5.01\left(\mathrm{H}-1^{\prime}\right)$ and $\delta_{\mathrm{H}} 4.58\left(\mathrm{H}-1^{\prime \prime}\right)$; and $\delta_{\mathrm{C}}$ $96.4\left(\mathrm{C}-1^{\prime}\right)$ and $\delta_{\mathrm{C}} 104.0\left(\mathrm{C}-1^{\prime \prime}\right)$, respectively. The first was established as $\alpha-$ axenose by HMBC, COSY, ROE correlations and NMR data comparison with literature ${ }^{38}$ (Supplementary Figure 3AG).

There are two ${ }^{1} \mathrm{H}$ spin systems from $\mathrm{H}-1^{\prime}$ to $\mathrm{H}-2^{\prime}$ and from $\mathrm{H}-4^{\prime}$ to $\mathrm{H}-6^{\prime}$; and HMBC correlations from methyl H-7 $7^{\prime}$ to $\mathrm{C}-2^{\prime}, \mathrm{C}^{-} 3^{\prime}$ and $\mathrm{C}^{\prime}$. Connection of this sugar to side chain of macrolactone was observed with $\mathrm{HMBC}$ correlations of $\mathrm{H}-1$ to $\mathrm{C}-41$. Small coupling constant of $\mathrm{H}-1^{\prime}$ and $\mathrm{H}-4$ 'suggested they should be in equatorial orientation. ROE correlation of $\mathrm{H}-41$ to $\mathrm{H}-5^{\prime}$ supported axial orientation of $\mathrm{H}^{-5}$.

The second sugar was established as $\beta$-amicetose. It was constructed by the ${ }^{1} \mathrm{H}$ spin system from $\mathrm{H}-1$ " ' to $\mathrm{H}-6^{\prime \prime}$. Large coupling constants ${ }^{3} \mathrm{~J}_{\mathrm{H}-1^{\prime \prime}, \mathrm{H}-2^{\prime \prime} \text { ax }}(7.6 \mathrm{~Hz})$ and ${ }^{3} J_{\mathrm{H}-4^{\prime \prime}, \mathrm{H}-5^{\prime \prime}}(9.3 \mathrm{~Hz})$; and ROE correlation between $\mathrm{H}-1^{\prime \prime}$ and $\mathrm{H}-5^{\prime \prime}$ ' suggested axial orientation of $\mathrm{H}-1^{\prime \prime}, \mathrm{H}-4^{\prime \prime}$ and $\mathrm{H}-5^{\prime \prime}$. Connection of both sugars was observed by the HMBC correlation of $\mathrm{H}-1^{\prime \prime}$ to C- 4 '. The HMBC correlation of $\mathrm{H}-$ 4 "' to C-50 connected the $\beta$-amicetose with the ester carbonyl group of naphthoquinone derivative moiety. ${ }^{1} \mathrm{H}$ NMR signals for $\mathrm{H}-54\left(\delta_{\mathrm{H}} 8.01\right), \mathrm{H}-61\left(\delta_{\mathrm{H}}\right.$ 8.07) and $\mathrm{H}-62\left(\delta_{\mathrm{H}} 7.79\right) ;{ }^{1} \mathrm{H}-{ }^{1} \mathrm{H}$ coupling constants ${ }^{3} J_{\mathrm{H}-54, \mathrm{H}-62}(1.3 \mathrm{~Hz})$ and ${ }^{3} J_{\mathrm{H}-61}$, $\mathrm{H}-62(8.0 \mathrm{~Hz})$; and ${ }^{1} \mathrm{H}^{1}{ }^{1} \mathrm{H}$ COSY correlations between $\mathrm{H}-54 / \mathrm{H}-62$ and $\mathrm{H}-61 / \mathrm{H}-62$ indicated the presence of an aromatic ring trisubstituted moiety. HMBC correlations of H-54 to C-56; H-61 to C-55 and C-59; H-62 to C-60; H-57 to C-55, C-59 and C-64; and H-64 to C-57, C-58, and C-59 indicated the presence of a quinone moiety methylated in $\mathrm{C}-58$ and connected to the aromatic ring. $\mathrm{HMBC}$ correlation of $\mathrm{H}-63$ to $\mathrm{C}-50, \mathrm{C}-51$ and $\mathrm{C}-52 ; \mathrm{H}-52$ to $\mathrm{C}-50$ and $\mathrm{C}-53 ; \mathrm{H}-54$ and $\mathrm{H}-$ 62 to C-52; evidence the connection of C-50, C-51, C-52, C-53 and C-63 to aromatic ring of naphthoquinone moiety. Compound 2 was named cyphomycin.

\section{Data availability}

Genomic data can be found at DOI: 10.5281/zenodo.2436565. All other data are available in the main text or the supplementary materials; Permits for collections and accessing genetic resources in Brazil were issued by SISBIO \#46555-5 and CNPq \#010936/2014-9. Costa Rican collecting permits were issued by the Comisión Institucional de Biodiversidad (Institutional Biodiversity Committee, University of Costa Rica; Resolutions \# 012 and 020; Material Transfer Agreement MTA VI-4307-2013) and authorized by La Selva Biological Station and Las Brisas Nature Reserve. A modified version of the southern pine beetle (Fig. 1) photo from Erich G. Vallery is used under the Creative Commons Attribution 3.0 License. Photos of Cyphomyrmex (Figs. 1 and 5) are used under a perpetual commercial license from Alexander Wild.

Received: 18 October 2018 Accepted: 11 January 2019

Published online: 31 January 2019

\section{References}

1. Sprenger, M. \& Fukuda, K. New mechanisms, new worries. Science 351, 1263-1264 (2016).

2. Brown, E. D. \& Wright, G. D. Antibacterial drug discovery in the resistance era. Nature 529, 336-343 (2016).

3. Newman, D. J. \& Cragg, G. M. Natural products as sources of new drugs from 1981 to 2014. J. Nat. Prod. 79, 629-661 (2016).

4. Lewin, G. R. et al. Evolution and ecology of actinobacteria and their bioenergy applications. Annu. Rev. Microbiol. 70, 235-254 (2016).

5. Baltz, R. H. Marcel Faber Roundtable: is our antibiotic pipeline unproductive because of starvation, constipation or lack of inspiration? J. Ind. Microbiol. Biotechnol. 33, 507-513 (2006).

6. Medema, M. H., Cimermancic, P., Sali, A., Takano, E. \& Fischbach, M. A. A systematic computational analysis of biosynthetic gene cluster evolution: lessons for engineering biosynthesis. PLoS Comput. Biol. 10, e1004016 (2014).

7. Doroghazi, J. R. et al. A roadmap for natural product discovery based on largescale genomics and metabolomics. Nat. Chem. Biol. 10, 963-968 (2014).

8. Smanski, M. J. et al. Synthetic biology to access and expand nature's chemical diversity. Nat. Rev. Microbiol. 14, 135-149 (2016).

9. Udwary, D. W. et al. Genome sequencing reveals complex secondary metabolome in the marine actinomycete Salinispora tropica. Proc. Natl Acad. Sci. USA 104, 10376-10381 (2007).

10. Ziemert, N. et al. Diversity and evolution of secondary metabolism in the marine actinomycete genus Salinispora. Proc. Natl Acad. Sci. USA 111 E1130-E1139 (2014).
11. Jang, K. H. et al. Anthracimycin, a potent anthrax antibiotic from a marinederived actinomycete. Angew. Chem. Int. Ed. 52, 7822-7824 (2013).

12. Schulze, C. J. et al. Genome-directed lead discovery: biosynthesis, structure elucidation, and biological evaluation of two families of polyene macrolactams against Trypanosoma brucei. ACS Chem. Biol. 150813113920008 (2015). https://doi.org/10.1021/acschembio.5b00308

13. Ling, L. L. et al. A new antibiotic kills pathogens without detectable resistance Nature 517, 455-459 (2015)

14. Pye, C. R., Bertin, M. J., Lokey, R. S., Gerwick, W. H. \& Linington, R. G. Retrospective analysis of natural products provides insights for future discovery trends. Proc. Natl Acad. Sci. USA 114, 5601-5606 (2017).

15. Miller, I., Chevrette, M. \& Kwan, J. Interpreting microbial biosynthesis in the genomic age: biological and practical considerations. Mar. Drugs 15, 165 (2017).

16. Clardy, J., Fischbacha, M. \& Currie, C. R. The natural history of antibiotics. Curr. Biol. 19, 1-8 (2009).

17. Adnani, N. et al. Coculture of marine invertebrate-associated bacteria and interdisciplinary technologies enable biosynthesis and discovery of a new antibiotic, keyicin. ACS Chem. Biol. 12, 3093-3102 (2017).

18. Zipperer, A. et al. Human commensals producing a novel antibiotic impair pathogen colonization. Nature 535, 511-516 (2016).

19. Oh, D.-C., Poulsen, M., Currie, C. R. \& Clardy, J. Dentigerumycin: a bacterial mediator of an ant-fungus symbiosis. Nat. Chem. Biol. 5, 391-393 (2009).

20. Currie, C. R. et al. Ancient tripartite coevolution in the attine ant-microbe symbiosis. Science 299, 386-388 (2003).

21. VanArnam, E. B. et al. Selvamicin, an atypical antifungal polyene from two alternative genomic contexts. Proc. Natl Acad. Sci. USA 113, 12940-12945 (2016).

22. Kroiss, J. et al. Symbiotic streptomycetes provide antibiotic combination prophylaxis for wasp offspring. Nat. Chem. Biol. 6, 261-263 (2010).

23. Scott, J. J. et al. Bacterial protection of beetle-fungus mutualism. Science 322, 63-63 (2008).

24. Blodgett, J. A. V. et al. Common biosynthetic origins for polycyclic tetramate macrolactams from phylogenetically diverse bacteria. Proc. Natl Acad. Sci. USA 107, 11692-11697 (2010).

25. Poulsen, M., Oh, D. C., Clardy, J. \& Currie, C. R. Chemical analyses of waspassociated Streptomyces bacteria reveal a prolific potential for natural products discovery. PLoS One 6, e16763 (2011).

26. Kim, K. H. et al. Natalamycin A, an Ansamycin from a termite-associated Streptomycessp. Chem. Sci. 5, 4333-4338 (2014).

27. Oh, D. C., Poulsen, M., Currie, C. R. \& Clardy, J. Sceliphrolactam, a polyene macrocyclic lactam from a wasp-associated Streptomyces sp. Org. Lett. 13, 752-755 (2011)

28. Carr, G. et al. Microtermolides A and B from termite-associated Streptomyces sp. and structural revision of vinylamycin. Org. Lett. 14, 2822-2825 (2012).

29. Stork, N. E., McBroom, J., Gely, C. \& Hamilton, A. J. New approaches narrow global species estimates for beetles, insects, and terrestrial arthropods. Proc. Natl Acad. Sci. USA 112, 7519-7523 (2015).

30. Eisner, T. \& Meinwald, J. Defensive secretions of arthropods. Science 153, 1341-1350 (1966)

31. Book, A. J. et al. Evolution of high cellulolytic activity in symbiotic Streptomyces through selection of expanded gene content and coordinated gene expression. PLoS Biol. 14, 1-21 (2016).

32. Chevrette, M. G. \& Currie, C. R. Emerging evolutionary paradigms in antibiotic discovery. J. Ind. Microbiol. Biotechnol. (2018). https://doi.org/ 10.1007/s10295-018-2085-6

33. Hug, J., Bader, C., Remškar, M., Cirnski, K. \& Müller, R. Concepts and methods to access novel antibiotics from actinomycetes. Antibiotics 7, 44 (2018).

34. McDonald, B. R. \& Currie, C. R. Lateral gene transfer dynamics in the ancient bacterial genus Streptomyces. mBio 8, e00644-17 (2017).

35. Blin, K. et al. antiSMASH 4.0-improvements in chemistry prediction and gene cluster boundary identification. Nucleic Acids Res. 1854, 1019-1037 (2017).

36. Navarro-Muñoz, J. et al. A computational framework for systematic exploration of biosynthetic diversity from large-scale genomic data. BioRxiv (2018) Preprint at https://doi.org/10.1101/445270.

37. Laatsch, H. Antibase: The Natural Compound Identifier (Wiley-VCH, Weinheim, 2014).

38. Pérez, M. et al. PM100117 and PM100118, new antitumor macrolides produced by a marine Streptomyces caniferus GUA-06-05-006A. J. Antibiot. 69, 388-394 (2016).

39. Takeuchi, T. et al. ATP depletion assay led to the isolation of new 36membered polyol macrolides Deplelides A and B from Streptomyces sp. MM581-NF15. Org. Lett. 19, 4207-4210 (2017).

40. Zhao, M. et al. In vivo pharmacokinetics and pharmacodynamics of APX001 against Candida spp. in a neutropenic disseminated candidiasis mouse model. Antimicrob. Agents Chemother. 62, e02542-17 (2018). 
41. Zhao, M., Lepak, A. J. \& Andes, D. R. Animal models in the pharmacokinetic / pharmacodynamic evaluation of antimicrobial agents. Bioorg. Med. Chem. 24, 6390-6400 (2016).

42. Andes, D. R. \& Lepak, A. J. In vivo infection models in the pre-clinical pharmacokinetic/pharmacodynamic evaluation of antimicrobial agents. Curr. Opin. Pharmacol. 36, 94-99 (2017).

43. Payne, D. J. Microbiology. Desperately seeking new antibiotics. Science 321 1644-1645 (2008).

44. Fisher, M. C., Hawkins, N. J., Sanglard, D. \& Gurr, S. J. Worldwide emergence of resistance to antifungal drugs challenges human health and food security. Science 360, 739-742 (2018).

45. Fischbach, M. A. \& Walsh, C. T. Antibiotics for emerging pathogens. Science 325, 1089-1093 (2009).

46. Hayakawa, M. \& Nonomura, H. Humic acid-vitamin agar, a new medium for the selective isolation of soil actinomycetes. J. Ferment. Technol. 65, 501-509 (1987).

47. Hanshew, A. S. et al. Characterization of actinobacteria associated with three ant-plant mutualisms. Microb. Ecol. 69, 192-203 (2015).

48. Li, Q., Chen, X., Jiang, Y. \& Jiang, C. in Actinobacteria - Basics and Biotechnological Applications (ed. Dhanasekaran, D.) (InTech, 2016). London, United Kingdom.

49. Katoh, K. \& Standley, D. M. MAFFT Multiple Sequence Alignment Software Version 7: improvements in performance and usability. Mol. Biol. Evol. 30, 772-780 (2013).

50. Price, M. N., Dehal, P. S. \& Arkin, A. P. FastTree 2 - approximately maximum-likelihood trees for large alignments. PLoS One 5, e9490 (2010).

51. Benjamini, Y. \& Yekutieli, D. The control of the false discovery rate in multiple testing under dependency. Ann. Stat. 29, 1165-1188 (2001).

52. Kumar, L. \& Futschik, M. E. Mfuzz: a software package for soft clustering of microarray data. Bioinformation 2, 5-7 (2007).

53. Liu, Y., Schröder, J. \& Schmidt, B. Musket: a multistage k-mer spectrum-based error corrector for Illumina sequence data. Bioinformatics 29, 308-315 (2013).

54. Magoč, T. \& Salzberg, S. L. FLASH: fast length adjustment of short reads to improve genome assemblies. Bioinformatics 27, 2957-2963 (2011).

55. Bankevich, A. et al. SPAdes: a new genome assembly algorithm and its applications to single-cell sequencing. J. Comput. Biol. 19, 455-477 (2012).

56. Hyatt, D. et al. Prodigal: prokaryotic gene recognition and translation initiation site identification. BMC Bioinforma. 11, 119 (2010).

57. Eddy, S. R. Accelerated profile HMM searches. PLoS Comput. Biol. 7, e1002195 (2011)

58. Stamatakis, A. RAxML version 8: a tool for phylogenetic analysis and postanalysis of large phylogenies. Bioinformatics 30, 1312-1313 (2014).

59. Medema, M. H. et al. Minimum information about a biosynthetic gene cluster. Nat. Chem. Biol. 11, 625-631 (2015).

60. Gritti, F. et al. Performance of columns packed with the new shell particles, Kinetex-C18. J. Chromatogr. A. 1217, 1589-1603 (2010).

61. Nielsen, K. F., Månsson, M., Rank, C., Frisvad, J. C. \& Larsen, T. O. Dereplication of microbial natural products by LC-DAD-TOFMS. J. Nat. Prod. 74, 2338-2348 (2011).

\section{Acknowledgements}

The authors would like to thank Daniel Udwary, Christina Hansen, Lindsay Kalan, Reed Stubbendieck, Charlotte Francoeur, Hongjie Li, and Jon Clardy for critical appraisal of the manuscript, and Steve Giles, Janet Newlands, Rachel Arango, Tim Aspenson,
Miranda Dam, Josh Daniels, Daniel DeSautels, Zachary Dumar, Athena Golfinos, Megan Hunjadi, Samuel Marquardt, Cathryn Phaybandyt, Mitchell Prokop, Shelby Sandstrom, Mia Temkin, and Aijan Urmat for technical help; This project was supported through National Institutes of Health (NIH) U19 Al109673, NIH U19 TW009872, National Science Foundation MCB-0702025, Sistema de Estudios de Posgrado y Vicerrectoría de Investigación de la Universidad de Costa Rica (research projects 801-B0-538 and 810B3-185), and São Paulo Research Foundation FAPESP grants \#2013/50954-0 (FAPESP/ FIC-NIH); \#2014/14095-6 (HEO); \#2015/01001-6 (WGPM). Additional support was provided to MGC through NIH National Research Service Award T32 GM008505.

\section{Author contributions}

Conceptualization: M.G.C., C.M.C., H.E.O., A.A.P., T.S.B., D.R.A., M.T.P., C.R.C.; Methodology: M.G.C., C.M.C., H.E.O., C.T., G.E.A., K.J.B., T.S.B., D.R.A., M.T.P., C.R.C.; Software: M.G.C.; Validation: M.G.C., C.M.C., H.E.O., G.E.A., M.Z., F.Z.; Formal analysis: M.G.C., H.E.O.; Investigation: M.G.C., C.M.C., H.E.O., C.T., G.E.A., K.J.B., W.F., J.J.K., L.M., W.G.P.M., H.A.H., A.A.P., E.W., A.S., S.W., M.Z., F.Z.; Resources: C.M.C., C.T., G.E.A., K.J.B., A.J.B., K.J.G., F.M.H., J.L.K., G.R.L., B.R.M., W.G.P.M., E.W., S.W., M.Z., F.Z., T.S.B., D.R.A., M.T.P., C.R.C.; Data curation: M.G.C., C.M.C.; WritingOriginal Draft: M.G.C., C.R.C.; Writing-Review and Editing: M.G.C., C.R.C., C.M.C., H.E.O., C.C., J.L.K., D.R.A., M.T.P., C.R.C.; Visualization: M.G.C.; Supervision: C.R.C., D.R.A., M.T.P., T.S.B., F.M.H.; Project administration: M.G.C., C.M.C., D.R.A., C.R.C.; Funding acquisition: T.S.B., D.R.A., M.T.P., C.R.C.

\section{Additional information}

Supplementary Information accompanies this paper at https://doi.org/10.1038/s41467 019-08438-0.

Competing interests: The authors declare no competing interests.

Reprints and permission information is available online at http://npg.nature.com/ reprintsandpermissions/

Journal peer review information: Nature Communications thanks the anonymous reviewers for their contribution to the peer review of this work.

Publisher's note: Springer Nature remains neutral with regard to jurisdictional claims in published maps and institutional affiliations.

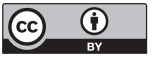

Open Access This article is licensed under a Creative Commons Attribution 4.0 International License, which permits use, sharing, adaptation, distribution and reproduction in any medium or format, as long as you give appropriate credit to the original author(s) and the source, provide a link to the Creative Commons license, and indicate if changes were made. The images or other third party material in this article are included in the article's Creative Commons license, unless indicated otherwise in a credit line to the material. If material is not included in the article's Creative Commons license and your intended use is not permitted by statutory regulation or exceeds the permitted use, you will need to obtain permission directly from the copyright holder. To view a copy of this license, visit http://creativecommons.org/ licenses/by/4.0/.

(C) The Author(s) 2019 